University of Minnesota Morris Digital Well

University of Minnesota Morris Digital Well

3-31-2020

\title{
Quantum Chemical Lipophilicities of Antimalarial Drugs in Relation to Terminal Half-Life
}

Joseph D. Alia

University of Minnesota - Morris, aliaj@morris.umn.edu

Sheila Karl

Tyler D. Kelly

Follow this and additional works at: https://digitalcommons.morris.umn.edu/chem_facpubs

Part of the Other Chemistry Commons

\section{Recommended Citation}

Alia J. D.; Karl S.; Kelly T. D. Quantum Chemical Lipophilicities of Antimalarial Drugs in Relation to Terminal Half-Life. ACS Omega. 2020, 5, 6500-6515.

This Article is brought to you for free and open access by the Faculty and Staff Scholarship at University of Minnesota Morris Digital Well. It has been accepted for inclusion in Chemistry Publications by an authorized administrator of University of Minnesota Morris Digital Well. For more information, please contact skulann@morris.umn.edu. 


\title{
Quantum Chemical Lipophilicities of Antimalarial Drugs in Relation to Terminal Half-Life
}

\author{
Joseph D. Alia,* Sheila Karl, and Tyler D. Kelly
}

Cite This: ACS Omega 2020, 5, 6500-6515

Read Online

ABSTRACT: According to the WHO, artemisinin-based combination therapies (ACTs) have been integral to the recent reduction in deaths due to Plasmodium falciparum malaria. ACT-resistant strains are an emerging problem and have evolved altered developmental stages, reducing exposure of the most susceptible stages to artemisinin drugs in popular ACTs. Lipophilicity, log $K_{\mathrm{ow}}$, is a guide in understanding and predicting pharmacokinetic properties such as terminal half-life which alters drug exposure. Consistent $\log K_{\mathrm{ow}}$ values are not necessarily available for artemisinin derivatives designed to extend terminal halflife, increase bioavailability, and reduce neurotoxicity. For other drugs used in ACTs, an assortment of experimental and computational log $K_{\mathrm{ow}}$ values are available in the literature and in some cases, do not account for subtle but important differences between closely related structures such as between diastereomers. Quantum chemical methods such as density functional theory

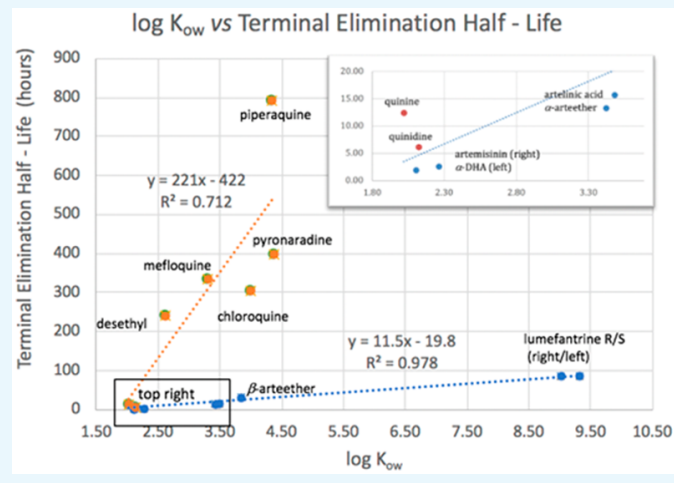
(DFT) used with an implicit solvent model allow for consistent comparison of physical properties including log $K_{\mathrm{ow}}$ and distinguish between closely related structures. To this end, DFT, B3LYP/6-31G(d), with an implicit solvent model (SMD) was used to compute $\Delta G_{\mathrm{ow}}^{\mathrm{o}}$ and $\Delta G_{\mathrm{vow}}^{\mathrm{o}}$ for 1-octanol-water and olive oil-water partitions, respectively, for 21 antimalarial drugs: 12 artemisininbased, 4 4-aminoquinolines and structurally similar pyronaridine, and 4 amino alcohols. The computed $\Delta G_{\text {ow }}^{o}$ was close to $\Delta G_{\text {ow }}^{o}$ calculated from experimental $\log K_{\mathrm{ow}}$ values from the literature where available, with a mean signed error of $2.3 \mathrm{~kJ} / \mathrm{mol}$ and mean unsigned error of $3.7 \mathrm{~kJ} / \mathrm{mol}$. The results allow assignment of $\log K_{\mathrm{ow}}$ for $\alpha$-and $\beta$-diastereomers of arteether, and prediction of log $K_{\mathrm{ow}}$ for $\beta$-DHA and five experimental drugs. Linear least square analysis of log $K_{\mathrm{ow}}$ and $\log K_{\mathrm{vow}}$ versus terminal elimination half-life showed strong linear relationships, once the data points for the 4-aminoquinoline drugs, mefloquine and pyronaridine were found to follow their own linear relationship, which is consistent with their different plasma protein binding. The linear relationship between the computed $\log K_{\mathrm{vow}}$ and terminal elimination half-life was particularly strong, $R^{2}=0.99$ and $F=467$, and can be interpreted in terms of a simple pharmacokinetic model. Terminal elimination half-life for $\beta$-DHA and four experimental artemisinin drugs were estimated based on this linear relationship between $\log K_{\text {vow }}$ and terminal $t_{1 / 2}$. The computed $\log K_{\text {ow }}$ and log $K_{\text {vow }}$ values for epimers $\alpha$ - and $\beta$-DHA and $\alpha$ and $\beta$-arteether provide physical data that may be helpful in understanding their different pharmacokinetics and activity based on their different molecular geometries. Relative solubility of quinine and quinidine are found to be sensitive to thermal corrections to enthalpy and to vibrational entropy and do not follow the general trend of longer terminal $t_{1 / 2}$ with greater predicted $\log K_{\mathrm{ow}}$. Geometric relaxation of $\alpha$ - and $\beta$-DHA in solvent and inclusion of thermal correction for enthalpy and entropy results in correct prediction that $\alpha$-DHA is favored in aqueous environments compared to $\beta$-DHA. Predictions made regarding experimental drugs have implications regarding their potential use in response to artemisinin drug-resistant strains.

\section{INTRODUCTION}

The World Health Organization, WHO, reported an estimated 219 million malaria cases with 435 thousand deaths in 2017 with most of these cases caused by the Plasmodium falciparum species of malaria, the predominant species in sub-Saharan Africa (99.7\%), South East Asia (62.8\%), the Eastern Mediterranean (69\%), and Western Pacific (71.9\%). ${ }^{1}$ According to the $\mathrm{WHO}$, nearly half the world's population was at risk of malaria in 2017 with $92 \%$ of cases and $93 \%$ of deaths taking place in Africa and 87 countries with active malaria transmission. Since 2010, malaria deaths per 100 thousand at risk have declined worldwide. ${ }^{1}$ The WHO considers artemisinin-based combination therapies, ACTs, as "integral to the recent success of global malaria control". ${ }^{1}$ The molecular structure of artemisinin with ring conformations and junctions determined by X-ray crystallography is shown in Figure 1. The molecular structures of dihydroartemisinin, DHA, and other artemisinin drugs used in ACTs are shown in Figure 2.

Received: December 4, 2019

Accepted: March 9, 2020

Published: March 23, 2020 


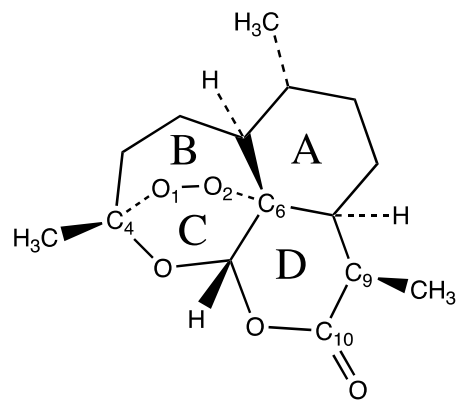

fused ring system

A - six membered ring - chair conformation B - seven membered ring containing oxygen bridge C - six membered ring with oxygen bridge and peroxide bridge D - six membered ring - distorted chair

cis ring junctions: $\mathrm{A} / \mathrm{B}, \mathrm{A} / \mathrm{D}, \mathrm{C} / \mathrm{D}$

trans ring junction: $\mathrm{B} / \mathrm{D}$ crystallography from the literature.

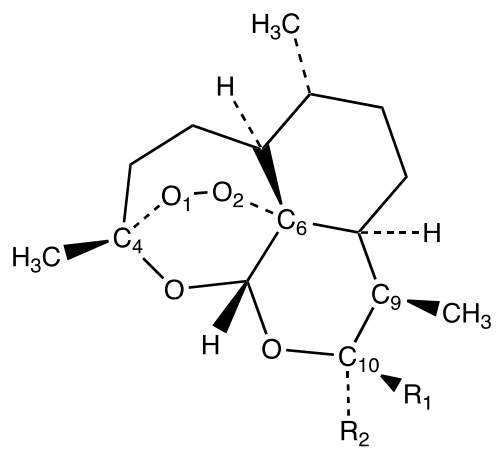

artemisinin Derivatives with substitution at $\mathbf{C}_{10}$

$\alpha$-dihydroartemisinin, $\alpha$-DHA. $\mathrm{R}_{1}=-\mathrm{H}, \mathrm{R}_{2}=-\mathrm{OH}$

$\beta$-dihydroartemisinin, $\beta$-DHA. R1 $=-\mathrm{OH}, \mathrm{R}_{2}=-\mathrm{H}$

artemether. $\mathrm{R}_{1}=-\mathrm{OMe}, \mathrm{R}_{2}=-\mathrm{H}$

$\alpha$-artheether. $\mathrm{R}_{1}=-\mathrm{H}, \mathrm{R}_{2}=-\mathrm{OEt}$

$\beta$-artheether. $\mathrm{R} 1=-\mathrm{OEt}, \mathrm{R}_{2}=-\mathrm{H}$

artesunic acid. $\mathrm{R}_{1}=-\mathrm{H}, \mathrm{R}_{2}=-\mathrm{OC}=\mathrm{OCH}_{2} \mathrm{CH}_{2} \mathrm{CO}_{2} \mathrm{H}$

artelinic acid. $\mathrm{R}_{1}=-\mathrm{OCH}_{2} p-\mathrm{CO}_{2} \mathrm{H}-\mathrm{C}_{6} \mathrm{H}_{4}, \mathrm{R}_{2}=-\mathrm{H}$

$\mathrm{F}_{1}$-DHA. $\mathrm{R}_{1}=-\mathrm{OCH}_{2} \mathrm{CH}_{2} \mathrm{CF}_{3}$

Figure 2. DHA and artemisinin derivatives with $-\mathrm{OR}$ substituents at $\mathrm{C}_{10}$.

According to Haldar et al. (2018), resistance has emerged to all antimalarial drugs in wide clinical use. ${ }^{2}$ In most regions where $P$. falciparum malaria is endemic, resistance to ACTs has not been observed. As of 2019, for example, ACTs, in particular artesunate + amodiaquine and artemether + lumefantrine, are efficacious and safe in Cameroon. ${ }^{3}$ Resistance differs from region to region. As of June 2019, artemisinin and ACT-resistant malaria is well established near the ThaiCambodia border and spreading through the Greater Mekong Sub-Region (GMS). ${ }^{4}$ Although ACTs typically have $>95 \%$ efficacy, from one to four ACTs now have $>10 \%$ failure rates in the GMS. ${ }^{1}$ Chloroquine-resistant malaria first emerged in the GMS before spreading to Africa. Such a pattern if followed by ACT resistance could be devastating. Better understanding of how the structures and resulting physical properties of current antimalarial drugs relate to their pharmacokinetics and antimalarial activity can provide a useful guide for the development of new drugs and drug therapies in the face of antimalarial drug resistance.

Artemisinin drugs in widely used ACTs have shorter elimination half-life and act quickly, eliminating most of the parasite population and quickly alleviating symptoms, while partner drugs with longer elimination half-life clear the remaining parasite population and guarantee the therapeutic outcome. Hott et al. (2015) found Cambodian F. falciparum strains with partial resistance to artemisinin drugs to have an extended ring stage and shortened trophozoite stage and hypothesized that this reduces drug exposure during stages when the parasite is most susceptible, elongates stages when it is less susceptible, and allows for ring stage dormancy to be triggered by DHA. ${ }^{5}$ These changes in parasite development however show less resistance to DHA than to artemisinin and artelinic acid, a drug never used clinically in the GMS. This indicates possible resistance against the artemisinin family of drugs rather than to specific artemisinin drugs. ${ }^{5}$ Chandra et al.
(2015) found regulation of glutathione with L-buthionine $(S, R)$-sulfoximine to increase the efficacy against arteetherresistant Plasmodium vinckei in mice, demonstrating a possible strategy for prolonging the use of artemisinin drugs against resistant strains. ${ }^{6}$ Hastings and Hodel (2014) note the use of combination therapy to slow or prevent drug resistance and argue for the importance of a pharmacological rather than a purely genetic approach toward understanding drug resistance as a basis for design of combination therapies and lowering effects of toxicity. ${ }^{7}$ Hastings et al. (2016) argue the short halflife of artemisinin drugs allow for their protection against resistance by ACT partner drugs that kill artemisinin-resistant strains but also leave the partner drugs as monotherapies making them more vulnerable to resistance. ${ }^{8}$ Hasting et al. (2016) discuss use of their pharmacological model to investigate how ACT design may target developmental stages of the malarial parasite. ${ }^{9}$ Perhaps artemisinin derivatives with longer half-life can help to protect their ACT partners while targeting parasite developmental stages more vulnerable to artemisinin drugs. Although more lipophilic artemisinin derivatives with longer elimination half-life offer greater exposure time, arteether, as an example, is not used as widely because it has slower absorption rates and higher risk of neurotoxicity. ${ }^{10}$ Wesche et al. (1994) found neurotoxicity of artemisinin drugs to be sensitive to substitution at $C_{9}$ and $C_{10}$ and found DHA and artesunate which rapidly converts to DHA in vivo to have the greatest neurotoxicity. ${ }^{11}$

Design and synthesis of new artemisinin-based drugs has had goals of increasing elimination half-life and bioavailability while decreasing possible neurotoxicity. Avery et al. (2002), for example, synthesized numerous $\mathrm{C}_{9}$ artemisinin derivatives and used in vitro and in vivo rodent evidence to narrow to the two most promising for drug development. ${ }^{12}$ Their molecular structures, Avery-14 the most economical and Avery-17 the most potent are shown in Figure $3 .^{12}$ Bigucci et al. (2008) 


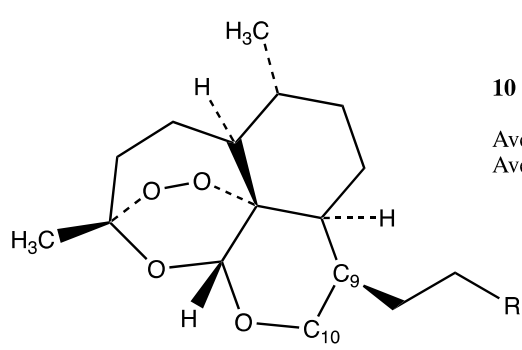

\section{0 -dexoartemisinin Derivatives with substitution at $\mathrm{C}_{9}$}

Avery et al. structure 14. $\mathrm{R}=3,4-\mathrm{Cl}_{2} \mathrm{C}_{6} \mathrm{H}_{3}$

Avery et al. structure 17. $\mathrm{R}=\mathrm{m}-\mathrm{CF}_{3} \mathrm{C}_{6} \mathrm{H}_{4}$

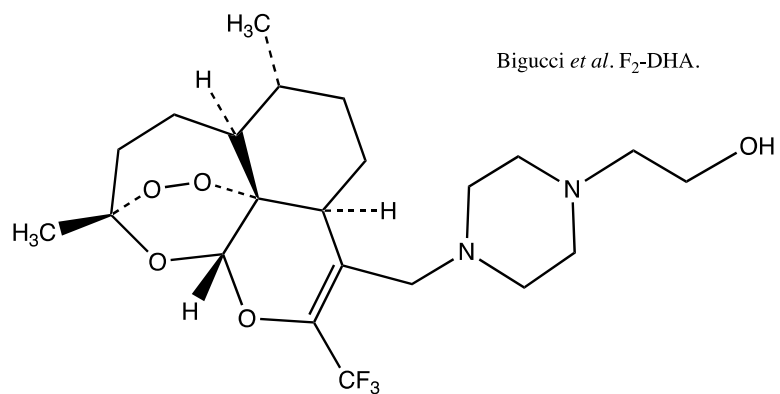

Figure 3. Artemisinin derivatives with substituents at $C_{9}$.<smiles>CCN(CC)c1cc(Nc2ccnc3cc(Cl)ccc23)ccc1O</smiles><smiles>CCNc1cc(Nc2ccnc3cc(Cl)ccc23)ccc1O</smiles>

amodiaquine

desethyl amodiaquine<smiles>Clc1ccc2c(N3CCN(CCCN4CCN(c5ccnc6cc(Cl)ccc56)CC4)CC3)ccnc2c1</smiles><smiles>CCN(CC)CCC[C@H](C)Nc1ccnc2cc(Cl)ccc12</smiles><smiles>C/C=C\Nc1c2cc(OC)c(Cl)cc2nc2cc(Cl)cnc12</smiles>

Figure 4. 4-Aminoquinoline-based antimalarial drugs used in ACT and structurally similar pyronaridine also used in ACT. 


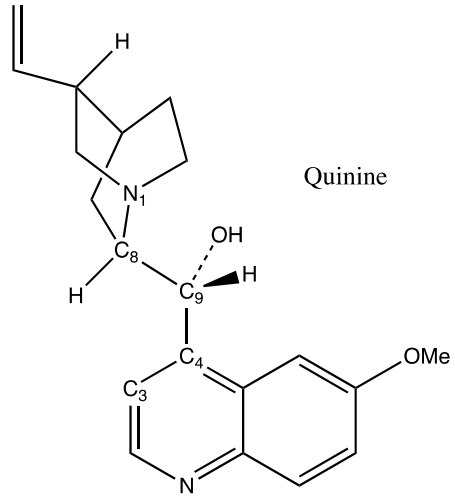<smiles>C=CC1(C)CN2CCC1C2[C@H](O)c1ccnc2ccc(OC)cc12</smiles>
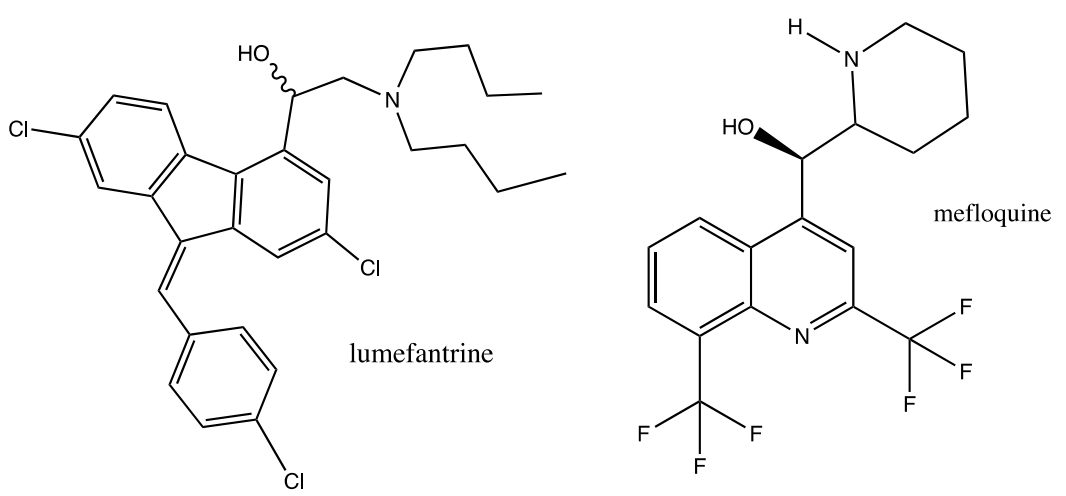

Figure 5. Quinolinemethanols quinine, quinidine, and mefloquine. Atom numbering for quinine and quinidine will be referred to in the Results and Discussion sections.

tested the bioavailability of two fluoroalkyl derivatives of DHA, $10 \beta$-(trifluoropropyloxy)dihydroartemisinin ( $\left.\mathrm{F}_{1}-\mathrm{DHA}\right)$, a $\mathrm{C}_{10}$ substituted compound shown in Figure 2, and 10-trifluoromethyl-16-[2-(hydroxyethyl)piperazine] $\left(\mathrm{F}_{2}-\mathrm{DHA}\right), \mathrm{C}_{9}$ and $\mathrm{C}_{10}$ substituted compound shown in Figure $3{ }^{13}$ They found evidence that the fluoroalkyl ether substitution and $\mathrm{C}_{10}$ in $\mathrm{F}_{1}$ DHA presents an obstacle for absorption across the intestinal lining and discuss these results in the context of solubility and their $\log K_{\text {oct:Ringer }}$ values of 1.89 for artemisinin, 4.50 for $F_{1}$ DHA, and 2.55 for $\mathrm{F}_{2}$-DHA. Their $\log K_{\text {oct:Ringer }}$ is lower than $\log K_{\mathrm{ow}}$ for artemisinin reported by Haynes et al. (2006), 2.94 (experimental), and 3.17 (computational). ${ }^{14}$ Consistent lipophilicity values where available allow for comparison of pharmacokinetic properties on a consistent basis. Methods of estimating $\log K_{\mathrm{ow}}$ values that allow for comparison on equal footing of a wide range of drugs based on their molecular structures can be a basis for estimating relative pharmacokinetic properties.

Computational approaches can, in some cases, quickly estimate physical properties such as $\log K_{\text {ow }}$ based on molecular structures and be effective tools for screening of potential drugs. Although widely used methods such as Clog $P^{15}$ based on molecular fragments and ALOGPS 2.1 based on computational neural networks can give quick results with high accuracy, they do not distinguish between diastereomers in their predicted $\log K_{\text {ow }}$ values. Clog $P$, for example, predicts quinine and quinidine to have the same log $K_{\text {ow }}$, whereas these two drugs are known to have different pharmacokinetics, protein binding, and antimalarial activity. ${ }^{19}$ Zaera et al. (2009) using NOESY NMR methods and density functional theory, DFT, computations found solubility differences between cinchona compound diastereomers to be attributable to differences in vibrational entropy resulting from a slight shift in the center of mass between diastereomers. $^{20}$ Quicker computational methods generally do not allow for as detailed an understanding of physical properties resulting from molecular structure. There may be a range of $\log K_{\mathrm{ow}}$ values available in the literature for a given compound and one may wonder which is most consistent with the drugs biological behavior. Quantum chemical methods such as DFT can be used with an implicit solvent model to predict molecular structural properties in far greater detail and with good accuracy but may become both impractical and less accurate with larger ( $>50$ atoms) molecules with more rotatable bonds. ${ }^{21}$ Such computations, when applied appropriately however, can give a consistent approach toward properties such as $\log K_{\mathrm{ow}}$ including subtle differences between closely related compounds such as diastereomers and can provide a consistent basis for understanding how structural properties are related to physical properties and biological behavior across a group of related compounds.

In this work, 21 antimalarial drugs from three families, artemisinin-based (Figures 1-3), 4-amino quinoline and structurally similar pyronaridine (Figure 4), and amino alcohols (Figure 5), are studied using DFT, B3LYP, and an implicit solvent model, SMD. Free-energy changes are computed for transfer from water to 1-octanol, $\Delta G_{\mathrm{ow}}^{\mathrm{o}}$, and from water to olive oil, $\Delta G_{\mathrm{vow}}^{\mathrm{o}}$. The computed $\Delta G_{\mathrm{ow}}^{\mathrm{o}}$ are compared to $\Delta G_{\text {ow }}^{\mathrm{o}}$ calculated from experimental $\log K_{\mathrm{ow}}$ values from the literature and errors examined to identify outliers. The results allow $\log K_{\mathrm{ow}}$ for three sets of diastereomers to be clarified and estimates of $\log K_{\mathrm{ow}}$ are made for five experimental antimalarial drugs, $\beta$-DHA, and the $\alpha$-and $\beta$ diastereomers of arteether. Linear relationships between log 
$K_{\text {ow }}$ and $\log K_{\text {vow }}$ and terminal elimination half-life are examined for $\log K_{\text {ow }}$ values computed using DFT and the SMD solvent model, $\log K_{\mathrm{ow}}$ computed using ALOGPS version 2.1 online, and experimental $\log K_{\mathrm{ow}}$ from the literature. Linear trends and statistical outliers are considered with regard to drug family and protein binding. The strong linear relationships that emerge can be interpreted using a simple pharmacokinetic model and allow estimates of terminal elimination half-life to be made for five experimental antimalarial drugs. Computed dipole moments and computational results including geometry relaxation in the different solvents allow some observed properties of diastereomers to be understood in terms of their polarity and computed entropies and enthalpies in different solvents.

\section{METHODS}

Geometry optimization of each drug was carried using the B3LYP $22-25$ hybrid density functional with the 6-31G(d) basis set and followed by vibrational analysis to confirm that a local minimum of energy was found, that is, all positive real vibrational frequencies. A first set of computations was carried out by coauthors TDK and SK using Gaussian 09, Revision B. $01^{26}$ and then confirmed with corrections and revisions where needed by JDA using Gaussian 16, Revision A.03. ${ }^{27}$ Input molecular structures for artemisinin and artemisinin derivatives were carefully checked to have ring conformations, ring junctions, and conformations as indicated by X-ray structures. $^{28-30}$ Piperaquine is known to have a number of thermally accessible conformers at room temperature. ${ }^{31}$ After making computations on several piperaquine conformers, a conformer similar to that displayed as the $3 \mathrm{D}$ geometry on PubChem was found to have the lowest in energy of those considered. $^{32}$ Interestingly, results from implicit solvent models including SMD are not significantly improved going from a single conformation approach to one involving an ensemble of conformations. ${ }^{21}$ It is common practice to use implicit solvent models with a single molecular conformation. ${ }^{33}$ The assumption in doing this is that differences in the vacuum and solvated distribution of conformers are negligible and have negligible enthalpic and entropic effects on the solvent. ${ }^{33}$ In this work, we use a single conformation methodology. An effort was made to use lowest energy conformations as supported by the literature but global energy minimum were not methodically searched. Quinine and quinidine are also known to have several thermally accessible conformers at room temperature. Experiment indicates that a cis- $\gamma$-open conformer is lowest in energy and this conformation was chosen for DFT geometry optimization in this work. ${ }^{34}$ Optimized gas phase geometries confirmed as local energy minima with all positive real vibrational frequencies were then used for calculations with the $\mathrm{SMD}^{35}$ solvent model also at the B3LYP/6-31G(d) level of theory. Examples for which experimental geometries were not found in the literature, the global minimum in energy conformation was assumed to be one matching qualitative steric reasoning and in some cases, geometries of several conformers were computed to find the lowest in energy of those considered. In the remainder of this paper, B3LYP/6-31G(d) computations with the SMD solvent model will be referred to as DFT for in vacuo computations and DFT-oct or DFT-olive according to the solvent being modeled. SMD solvent descriptors for water were those included with Gaussian 09 and Gaussian 16. Those for olive oil were added to input files manually and are shown in Table
$1 .^{36,37}$ It was found that the 1-octanol parameters from the Minnesota Solvent Descriptor Database ${ }^{38}$ lead to a systematic

Table 1. Olive Oil Solvent Descriptors Used in Implicit Solvation Computations ${ }^{a}$

\begin{tabular}{lc}
\multicolumn{1}{c}{ descriptor } & olive oil $^{b}$ \\
Eps & 3.109 \\
EpsInf & 2.155 \\
HBondAcidity & 0.19 \\
HBondBasicity & 0.45 \\
SurfaceTensionAtInterface & 32.80 \\
CarbonAromaticity & 0.0 \\
ElectronegativeHalogenicity & 0.0
\end{tabular}

${ }^{a}$ Descriptors are designated according to their keywords in Gaussian software. ${ }^{b}$ Chamberlin et al. (2008) and private communication with Gaussian technical support.

error of about $11 \mathrm{~kJ} / \mathrm{mol}$, underestimating solubilities in 1octanol compared to water when used with G09 and G16 implementations of SMD, whereas use of the scrf $=(S M D$, solvent $=n$-octanol) command to utilize built-in parameters for 1-octanol removed this systematic error.

Partitioning of a solute between solvents depends on the relative thermodynamic stability of the solute in each solvent at constant temperature and pressure and therefore the difference in Gibbs free energy of the solute in each solvent, in this case,

$$
\Delta G_{\mathrm{ow}}^{\mathrm{o}}=G_{\text {organic }}^{\mathrm{o}}-G_{\text {water }}^{\mathrm{o}}
$$

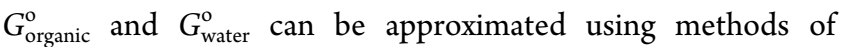
quantum chemistry and an implicit solvent model. $\log K_{\text {ow }}$ may then be calculated according to

$$
\log K_{\mathrm{ow}}=\frac{-\Delta G_{\mathrm{ow}}^{\mathrm{o}}}{R T \ln (10)}
$$

Values of $\log K_{\mathrm{ow}}$ for 1-octanol-water partitions and $\log$ $K_{\text {vow }}$ for olive oil-water partitions from computational results were calculated by eqs 1 and 2. Equation 2 was likewise used to convert $\log K_{\text {ow }}$ values from the literature to $\Delta G_{\text {ow }}^{\text {o }}$ to compare with the computed $\Delta G_{\mathrm{ow}}^{\mathrm{o}}$. The computational neural network program ALOGPS 2.1 $1^{18}$ accessed online ${ }^{16,17}$ was used to compute $\log K_{\mathrm{ow}}$ values in two ways that in some cases gave different results: (1) using the SMILES descriptor found on PubChem $^{32}$ and (2) using the DFT-optimized geometry in .mol2 format.

A second aspect of this work was the comparison of computed $\log K_{\mathrm{ow}}$ values and those from the literature to terminal elimination half-life. An effort was made to use consistent terminal elimination half-life, that is, healthy adult human subjects given oral dosage not in combination with other drugs and not after repeated dosing. When terminal elimination half-life for human subjects were not available, those for rats were converted to estimated elimination half-life for humans. ${ }^{39}$ Literature $\log K_{\mathrm{ow}}$ values were experimental where available but otherwise, computed estimates available in the literature were used and software specified.

The terminal elimination half-life is defined as the time required for the blood plasma concentration of the drug to decrease by half after a pseudo-equilibrium (steady-state) distribution has been reached. ${ }^{40}$ This definition in terms of a pseudo-equilibrium property is the basis for expecting a clear relationship between terminal $t_{1 / 2}$ and $\log K_{\mathrm{ow}}$ which is based 
on $\Delta G_{\text {ow }}^{\mathrm{o}}$. In cases for which the simplest one-compartment pharmacokinetic behavior applies, the terminal elimination half-life is based on the unbound steady-state distribution volume, $V_{\mathrm{d}, \mathrm{ss}, \mathrm{u}}$ and the unbound clearance, $\mathrm{CL}_{\mathrm{u}}$.

$$
t_{1 / 2}=\frac{V_{\mathrm{d}, \mathrm{ss}, \mathrm{u}}}{\mathrm{CL}_{\mathrm{u}}} \ln (2)=\frac{\ln 2}{k}
$$

$V_{\mathrm{d}, \mathrm{s} s, \mathrm{u}}$ is the volume required to contain the total steady-state amount of the drug at concentration equal to its steady-state unbound blood concentration, and $\mathrm{CL}_{\mathrm{u}}$ is a proportionality constant relating the rate of elimination to the total amount of drug in circulation. ${ }^{41}$

The rate constant, $k$, is for the overall terminal stage firstorder process of elimination. Broccatelli et al. (2018) identify a selection of terminal half-life efficient molecular structural modifications which increase both $V_{\mathrm{d}, \mathrm{ss}, \mathrm{u}}$ and $\mathrm{CL}_{\mathrm{u}}$ with lipophilicity. ${ }^{41}$ Where one value of $k$ is appropriate for a series of drugs, a consistent value for $V_{\mathrm{d}, \mathrm{ss}, \mathrm{u}} / \mathrm{CL}_{\mathrm{u}}$ is implied.

We use a simple pharmacokinetic model to interpret linear relationships between terminal $t_{1 / 2}$ and $\log K_{\text {ow }}$. The drug in a lipophilic environment is $D_{\mathrm{o}}$, in an aqueous environment, $D_{\mathrm{w}}$, and the drug after a rate-determining elimination process step is $D_{\text {elim }}$. According to the definition of terminal elimination half-life, $D_{\mathrm{w}}$ has a steady-state concentration, $\left[D_{\mathrm{w}}\right]$. According to the simplest possible pharmacokinetic model, elimination in the terminal phase is first order.

$$
D_{\mathrm{o}} \rightleftarrows D_{\mathrm{w}} \stackrel{k_{\text {elim }}}{\longrightarrow} D_{\text {elim }}
$$

with $\left[D_{\mathrm{o}}\right] \approx[D]$ for highly lipophilic drugs, elimination from the aqueous phase is much slower than equilibration of the drug between lipophilic and aqueous environments, and using the steady-state approximation

$$
\begin{aligned}
& \text { Rate } \approx \frac{-k_{\text {elim }}}{K_{\mathrm{ow}}}[D] \approx \frac{-k_{\text {elim }}}{\left(-\frac{\Delta G_{\mathrm{ow}}^{\mathrm{o}}}{R T}+1\right)}[D] \\
& \text { and } k \approx \frac{-k_{\mathrm{elim}}}{\left(-\frac{\Delta G_{\mathrm{ow}}^{\mathrm{o}}}{R T}+1\right)}=\frac{-k_{\mathrm{elim}}}{\left(\ln (10) \log K_{\mathrm{ow}}+1\right)}
\end{aligned}
$$

Substituting $k$ into the expression for $t_{1 / 2}$ from first-order kinetics

$$
t_{1 / 2}=\frac{\ln 2}{k}=\left(\frac{\ln (2) \ln (10)}{k_{\text {elim }}}\right) \log K_{\mathrm{ow}}+\frac{\ln 2}{k_{\text {elim }}}
$$

In cases where this linear relationship between $t_{1 / 2}$ and log $K_{\text {ow }}$ holds, we expect slope $=\ln (10) \times$ intercept and $k_{\text {elim }}$ in the context of this simple model to be $k_{\text {elim }}=(\ln (2) \ln (10)) /$ slope.

Linear least squares analysis and $95 \%$ certainty ranges were calculated using the LINEST function from MS-Excel and predictions of $\log K_{\text {ow }}$ and terminal elimination half-lives for experimental drugs were made according to eq 7 with student $t_{0.95, n-2}$ from MS-EXCEL ${ }^{42}$ Unless stated otherwise, computed error ranges are $95 \%$ certainty ranges.

$$
\left(\hat{m} x_{\mathrm{p}}+\hat{b}\right) \pm t_{0.95, n-2} s_{x y} \sqrt{1+\frac{1}{n}+\frac{\left(x_{\mathrm{p}}-\bar{x}\right)^{2}}{S S_{x x}}}
$$

Outliers in plots of $\log K_{\text {ow }}$ versus terminal elimination halflife were identified according to their standardized residuals, $e_{i}^{*}$, calculated according to eq 8 , where $\alpha$ is the standard error, $e_{i}$ is residual for point $i$, and $h_{i}$ is leverage.

$$
\begin{aligned}
& e_{i}^{*}=\frac{e_{i}}{\hat{\sigma} \sqrt{h_{i}-1}} \quad \text { where } h_{i}=\frac{1}{n}+\frac{\left(x_{i}-\bar{x}\right)^{2}}{S S_{x x}} \text { and } \\
& S S_{x x}=\sum_{i}\left(x_{i}-\bar{x}\right)^{2}
\end{aligned}
$$

Standardized residuals for outliers were typically several times greater than those for other data points and consistent across regressions using all sources of $\log K_{\mathrm{ow}}$. Outliers were most clearly distinguished for the $\log K_{\text {ow }}$ from DFT-oct and because our focus was the application of this method, these data were used to select outliers where there was less distinction using other sources of $\log K_{\mathrm{ow}}$.

\section{RESULTS}

Accurate optimized geometries are important to results that follow, hence, comparison to literature geometries are presented first. To evaluate the accuracy and systematic errors in computed transfer free energies, $\Delta G_{\mathrm{ow}}^{\mathrm{o}}$, computed values were compared to those calculated from the literature, that is $\log K_{\mathrm{ow}}$ values, and the mean signed error was found to be 2.3 $\mathrm{kJ} / \mathrm{mol}$. Several compounds were found to have errors outside of a $99.9 \%$ certainty range and these outliers will be discussed later. Computed and literature $\log K_{\mathrm{ow}}$ values were compared to the terminal elimination half-life from the literature, outliers identified, and terminal elimination half-lives estimated for the experimental drugs and for $\beta$-DHA.

Accuracy of Computed Geometries. The endoperoxide linkage is known to be a requirement for the antimalarial activity of artemisinin drugs. Its bond lengths, angles, and torsional angle are sensitive to correct ring conformations, so comparison of these to experimental values is evidence of correct computed geometries. Endoperoxide bond lengths and angles for artemisinin, $\beta$-arteether, and $\beta$-DHA are compared to those from $\mathrm{X}$-ray crystal structures from the literature in Table S1 in the Supporting Information and show strong agreement. Endoperoxide bond lengths and angles for $\alpha$ arteether and $\alpha$-DHA are also included. To our knowledge, $\mathrm{X}$ ray structures for $\alpha$-DHA have not been reported in the literature. These bond lengths and angles are close to those for $\beta$-arteether and $\beta$-DHA, perhaps indicating that differences in antimalarial activity are not due to chemical reactivity of the endoperoxide group but to differences in physical properties such as lipophilicity.

Bond lengths and angles for optimized geometries of the most stable conformer for quinine and quinidine, cis $\gamma$ open (3), match those for similar computations in the literature for these drugs, which is in agreement with NMR studies in solution. The torsional angles given in Table S2 are most relevant to this lowest energy conformation. Also see the atom numbering scheme for quinine and quinidine in Figure 5.

Computed $\Delta G_{\text {ow }}^{\text {ow }}$ Compared to $\Delta G_{\text {ow }}^{\circ}$ Based on the Literature log $K_{\mathrm{ow}}$. Comparison of $\Delta G_{\mathrm{ow}}^{\mathrm{o}}$ computed using DFT-oct to $\Delta G_{\mathrm{ow}}^{\mathrm{o}}$ calculated from the literature $\log K_{\mathrm{ow}}$ values using eq 2 gives an indication of the accuracy of these computations (see Table 2). The $\Delta G_{\mathrm{ow}}^{\mathrm{o}}$ values DFT-oct are mostly not as negative as those calculated from $\log K_{\mathrm{ow}}$ from the literature, that is, they underestimate solubility in 1-octanol compared to water. Mean unsigned errors expected from the use of the SMD solvent model vary with the functional group. ${ }^{35}$ For example, for SMD used with B3LYP/6-31G(d), water-organic transfer free energies for aromatic $\mathrm{N}$-heterocycles and bifunctional $\mathrm{H}, \mathrm{C}, \mathrm{N}$ compounds are 3.0 and $3.6 \mathrm{~kJ}$ 
Table 2. $\Delta G_{\text {ow }}^{\mathrm{o}}$ from DFT-oct Compared to $\Delta G_{\mathrm{ow}}^{\mathrm{o}}$ Calculated from the Literature $\log K_{\mathrm{ow}}$ Values $\left(\mathrm{kJ} \mathrm{mol}^{-1}\right)$

\begin{tabular}{lcc}
\multicolumn{1}{c}{ drug } & $\Delta G_{\text {ow }}^{\mathrm{o}}(\mathrm{DFT}$-oct $)$ & $\Delta G_{\mathrm{ow}}^{\mathrm{o}}(\mathrm{lit})$ \\
artemisinin & -12.29 & $-16.782^{a}$ \\
$\alpha$-DHA & -12.03 & $-13.414^{a}$ \\
$\beta$-DHA & -14.46 & $-15.583^{a}$ \\
artemether & -18.50 & $-20.149^{b}$ \\
$\alpha$-arteether & -19.53 & $-22.204^{c}$ \\
$\beta$-arteether & -21.91 & $-22.204^{c}$ \\
artesunic acid & -10.74 & $-15.811^{a}$ \\
artelinic acid & -19.88 & $-25.743^{d}$ \\
$\mathrm{~F}_{1}$-DHA & -25.80 & $-25.686^{e}$ \\
F-DHA & -18.38 & $-14.555^{e}$ \\
amodiaquine & -17.64 & $-24.316^{f}$ \\
desethyl amodiaquine & -14.90 & $-18.894^{f}$ \\
piperaquine & -24.71 & $-33.106^{g}$ \\
chloroquine & -22.83 & $-26.942^{f}$ \\
quinine & -11.53 & $-15.069^{h}$ \\
quinidine & -12.12 & $-16.441^{h}$ \\
mefloquine & -18.85 & $-22.261^{i}$ \\
lumefantrine- $R$ & -53.21 & $-47.605^{j}$ \\
lumefantrine- $S$ & -51.47 & $-47.605^{j}$ \\
pyronaridine & -24.96 & $-28.426^{k}$
\end{tabular}

${ }^{a}$ Haynes et al. (2006). ${ }^{14}{ }^{b}$ Avery et al. (1995). ${ }^{43}{ }^{c}$ Ramu and Baker (1995) ${ }^{44}$ Singh and Chaudhary (2006). ${ }^{45}{ }^{d}$ Abraham and Acree (2013). ${ }^{46}{ }^{e}$ Bigucci et al. (2008). ${ }^{13} f_{\text {Warhurst et al. (2003). }{ }^{47} g_{\text {Public }}}$ assessment report (2011). ${ }^{48}{ }^{h}$ Warhurst et al. (2003) ${ }^{19}$ reporting values from Tsai et al. (1993). ${ }^{i}$ Strauch et al. (2011). ${ }^{49}$ Wahajuddin et al. (2014). ${ }^{50}{ }^{k}$ Crowe et al. (2006). ${ }^{51}$

mol $^{-1}$, respectively. ${ }^{35}$ The mean unsigned error for the results in Table 2 is $3.7 \mathrm{~kJ} \mathrm{~mol}^{-1}$. Piperaquine, amodiaquine, and lumefantrine $R$ and $S$ enantiomers have errors that do not fall within a $99.9 \%$ certainty range and will be discussed later.

Predicted $\log K_{\mathrm{ow}}$ for experimental antimalarial drugs and for diastereomers for which assignment of $\log K_{\mathrm{ow}}$, to our knowledge, is not available, are shown in Table 3. The log

Table 3. Predicted $\log K_{\mathrm{ow}}$ Values Based on $\Delta G_{\mathrm{ow}}^{\mathrm{o}}$ from DFT-oct

\begin{tabular}{lc}
\multicolumn{1}{c}{ drug } & predicted $\log K_{\mathrm{ow}}$ \\
artelinic acid & 3.48 \\
Avery-14 & 5.92 \\
Avery-17 & 5.69 \\
$\mathrm{~F}_{1}$-DHA & 4.52 \\
$\mathrm{~F}_{2}$-DHA & 3.22 \\
$\alpha$-DHA & 2.11 \\
$\beta$-DHA & 2.53 \\
$\alpha$-artheeter & 3.42 \\
$\beta$-artheether & 3.84 \\
\hline
\end{tabular}

$K_{\text {ow }}$ for artelinic acid has been predicted using other computational methods; BioLoom gives $4.51,{ }^{46}$ PubChem $^{52}$ gives an XLogP3-AA ${ }^{53}$ value of 4.1, and ALOGPS 2.1 gives 3.79 when artelinic acid's SMILES descriptor is used as input and 2.06 when artelinic acid's DFT-optimized geometry is submitted in .mol2 format (see Table 4). Experimental and computed $\log K_{\mathrm{ow}}$ reported in the literature do not distinguish between $\alpha$ - and $\beta$-isomers of arteether (see Table 4). The $\alpha$ and $\beta$-isomers of arteether and DHA have different pharmacokinetics and antimalarial activity reflecting their different structures and different lipophilicity. The $\log K_{\text {ow }}$ for individual isomers may accordingly be useful. Predictions of these are in Table 3.

Comparison to Terminal Elimination Half-Life. Computed and literature, $\log K_{\text {ow }}$ and $\log K_{\text {vow }}$, values are compared with elimination half-life for each drug in Table 4. Terminal elimination half-life was not available for $\beta$-DHA, $\mathrm{F}_{1}-\mathrm{DHA}, \mathrm{F}_{2}$ DHA, Avery 14, and Avery 17. Amodiaquine is quickly converted in vivo to desethyl amodiaquine, so, elimination halflife given for it is either short and reflects this chemical conversion or long and reflects the pharmacokinetics of desethyl amodiaquine. ${ }^{59}$ Artesunic acid in vivo is quickly hydrolyzed to DHA. ${ }^{59}$ Artemether's steady-state plasma levels reflect its rapid conversion to DHA in patients and healthy subjects dosed orally. ${ }^{56}$ The steady-state plasma concentrations of arteether, on the other hand, are high compared to its metabolite DHA. ${ }^{66}$ Amodiaquine, artesunic acid, and artemether have steady-state plasma concentrations reflecting their relatively fast chemical conversion and therefore their log $K_{\mathrm{ow}}$ values cannot be expected to be as good an indicator of their terminal elimination half-life as drugs that are either converted to their metabolites less rapidly or to a lesser extent. Amodiaquine, artesunic acid, and artemether are therefore not included in the linear least squares analysis to be discussed next.

Linear least square regressions of $\log K_{\mathrm{ow}}$ from DFT-oct, log $K_{\mathrm{ow}}$ (lit), $\log K_{\mathrm{ow}}$ from ALOGPS 2.1, and $\log K_{\mathrm{vow}}$ from DFTolive versus elimination half-life were made. Omission of worst outliers for the $\log K_{\mathrm{ow}}$ from DFT-oct versus terminal elimination half-life regressions for each consecutive regression resulted in statistical outliers being removed in the following order: piperaquine, pyronaridine, mefloquine, chloroquine, and desethyl amodiaquine. Piperaquine was a strong outlier regardless of the source of $\log K_{\mathrm{ow}}$. Subsequent choice of the worst outlier was not necessarily clear for log $K_{\text {vow }}$ (olive oilwater) regressions; however, the compounds omitted based on $\log K_{\mathrm{ow}}$ regressions also improved the olive oil-water $\log K_{\mathrm{vow}}$ linear fits markedly. The compounds omitted were all quinoline-based antimalarial drugs and pyronaridine which has strong structural similarities to the quinoline-based drugs. It is interesting that quinine and quinidine have much different elimination half-life than the other quinoline-based drugs. The remaining drugs were artemisinin-based drugs, quinine and quinidine, and lumefantrine, that is, artemisinin drugs and amino alcohols. Linear regression results for the remaining ten compounds, artemisinin, $\alpha$-DHA, $\beta$-DHA, $\alpha$-arteether, $\beta$ arteether, artelinic acid, quinine, quinidine, and $\mathrm{R}$ and $\mathrm{S}$ enantiomers of lumefantrine are shown in Table 5.

The computed $\log K_{\text {vow }}$ for olive oil-water partitioning have the strongest linear relationship with terminal elimination half -life for this subset of compounds and the relationship between slope and intercept is close to the prediction based on the simple kinetic model presented in the Methods section. The certainty range for the slope, 9.21-10.97, is within the $95 \%$ certainty range of the intercept multiplied by $\ln (10)$, that is $1.04-17.15$ h. Calculated from the slope, $k_{\text {elim }}=0.158 \pm 0.014$ $\mathrm{h}^{-1}$. The plot and best fit line are shown in Figure 6. Figure S1 in the Supporting Information includes $\log K_{\mathrm{ow}}$ from the lit., DFT-oct, DFT-olive, and ALOGPS 2.1 with SMILES input versus terminal $t_{1 / 2}$ and individual trend lines for each method, and lumefantrine data is included.

The strong linear relationships found between $\log K_{\mathrm{ow}}$ from DFT-oct and terminal elimination half-life for these drugs 
Table 4. $\log K_{\mathrm{ow}}$ and $\log K_{\mathrm{vow}}$ from DFT-oct, $\log K_{\mathrm{ow}}$ (Lit), ALOGPS 2.1, and Elimination Half-Lives for Healthy Adult Subjects

\begin{tabular}{|c|c|c|c|c|c|c|}
\hline compound & $\log K_{\text {ow }}$ (DFT-oct) & $\log K_{\text {ow }}\left(\right.$ lit. $\left.^{a}\right)$ & $\log K_{\text {ow }}\left(\right.$ ALOGPS $\left.2.1^{b}\right)$ & $\log K_{\text {ow }}\left(\right.$ ALOGPS $\left.2.1^{c}\right)$ & $\log K_{\text {vow }}(\mathrm{DFT}$-olive $)$ & $t_{1 / 2}(\mathrm{~h})$ \\
\hline artemisinin & 2.26 & 2.94 & 2.52 & 1.23 & 0.489 & $2.6^{e}$ \\
\hline$\alpha$-DHA & 2.11 & 2.35 & 2.25 & 0.86 & -0.483 & $1.86^{e}$ \\
\hline artemether & 3.24 & 3.53 & 3.02 & 1.48 & 1.56 & $3.10^{g}$ \\
\hline$\alpha$-arteether & 3.42 & 3.89 & 3.52 & 1.94 & 1.45 & $13.24^{h}$ \\
\hline$\beta$-arteether & 3.84 & 3.89 & 3.52 & 1.94 & 2.196 & $30.17^{h}$ \\
\hline artesunic acid & 1.88 & 2.77 & 2.35 & 0.93 & -1.56 & $0.70^{i}$ \\
\hline artelinic acid & 3.48 & $4.51^{d}$ & 3.79 & 2.06 & 1.197 & $15.63^{i}$ \\
\hline amodiaquine & 3.09 & 4.26 & 4.83 & 4.83 & 0.621 & $5.3^{j}$ \\
\hline desethyl amodiaquine & 2.61 & 3.31 & 3.96 & 3.96 & 0.396 & $240^{j}$ \\
\hline piperaquine & 4.33 & 5.8 & 5.53 & 5.53 & 2.620 & $792^{k}$ \\
\hline chloroquine & 4.00 & 4.72 & 5.28 & & 2.72 & $304^{l}$ \\
\hline quinine & 2.02 & 2.64 & 2.82 & 2.82 & 0.207 & $12.34^{m}$ \\
\hline quinidine & 2.12 & 2.88 & 2.82 & 2.82 & 0.363 & $6.09^{p}$ \\
\hline mefloquine & 3.30 & 3.90 & 3.10 & 3.10 & 1.09 & $334^{n}$ \\
\hline lumefantrine $(R / S)$ & $9.32 / 9.02$ & 8.6 & 8.34 & 8.34 & 8.176 & $86^{\circ}$ \\
\hline pyronaridine & 4.37 & 5.78 & 5.78 & & 2.246 & $397^{f}$ \\
\hline
\end{tabular}

${ }^{a}$ See references for $\Delta G_{\mathrm{ow}}^{\mathrm{o}}$ (lit.) given in Table 2. ${ }^{b}$ Isomeric SMILES identifier submitted to ALOGPS $2.1^{18}$ accessed on 10 October 2019 and before through http://www.vcclab.org/web/alogps/. ${ }^{c}$ B3LYP/6-31G(d) optimized geometry in .mol2 format submitted to ALOGPS $2.1^{18}$ accessed through http://www.vcclab.org/web/alogps/ on 10 October 2019 and earlier. ${ }^{d}$ Calculated value BioLoom and presented in Table 2 of Abraham

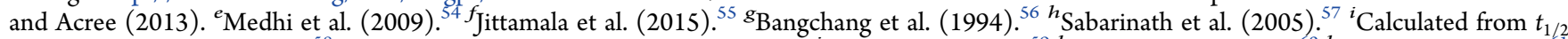
rat data from Si et al. $(2007)^{58}$ using eq 6 in Table 1 in Sarver et al. (1997). ${ }^{j}$ Orrell et al. (2008). ${ }^{59}{ }^{k}$ Tarning et al. (2005). ${ }^{60}{ }^{l}$ Moore et al. (2011). ${ }^{61}$ ${ }^{m}$ Babalola et al. (1997). ${ }^{62}{ }^{n}$ Stauch et al. (2011). ${ }^{o}$ Nosten and White (2007), ${ }^{63}$ Lefêvre and Thomsen (1999): $71.3 \mathrm{~h} \mathrm{(fed)} 35.1 \mathrm{~h}$ (fasted) Lefêvre and Thomsen (1999). ${ }^{64}{ }^{p}$ Ochs et al. (1978). ${ }^{65}$

Table 5. Artemisinin-Based Drugs and Amino Alcohol Linear Least Square Results for Computed and Literature $\log K_{\text {ow }}$ vs Terminal Elimination Half-Life from the Literature $^{a}$

\begin{tabular}{lcrcc}
\multicolumn{1}{c}{ method } & slope & intercept & \multicolumn{1}{c}{$R^{2}$} & \multicolumn{1}{c}{$F$} \\
$\log K_{\text {ow }}$ DFT-oct & $11.5 \pm 0.7$ & $-20 \pm 3$ & 0.978 & 309 \\
$\log K_{\text {vow }}$ DFT-olive & $10.1 \pm 0.5$ & $4 \pm 2$ & 0.985 & 467 \\
$\begin{array}{l}\log K_{\text {ow }} \text { ALOGPS 2.1 SMILES } \\
\text { input }\end{array}$ & $13.9 \pm 0.9$ & $-31 \pm 4$ & 0.975 & 268 \\
$\begin{array}{l}\log K_{\text {ow }} \text { ALOGPS 2.1.mol2 } \\
\quad \text { input }\end{array}$ & $12 \pm 1$ & $-10 \pm 5$ & 0.924 & 85 \\
$\log K_{\text {ow }}$ literature & $14 \pm 1$ & $-30 \pm 6$ & 0.947 & 124
\end{tabular}

${ }^{a}$ Slopes and intercepts are given with their standard deviations. allow terminal elimination half-life for experimental artemisinin drugs to be estimated. See Table 6 .

When $\log K_{\text {ow }}$ values for quinoline-based drugs and pyronaridine are compared to their terminal elimination halflife, the resulting relationships are not nearly as strong. Piperaquine has an exceptional standardized deviation for the linear least squares analysis using computational $\log K_{\mathrm{ow}}$ but not the literature $\log K_{\mathrm{ow}}$, and this is reflected in the higher $R^{2}$ and $F$ values when the literature $\log K_{\mathrm{ow}}$ values are used. For piperaquine, desethyl amodiaquine, quinine, quinidine, mefloquine, chloroquine, and pyronaridine, log $K_{\mathrm{ow}}$ values from DFT-oct and from the literature show a stronger linear relationship than $\log K_{\mathrm{ow}}$ from ALOGPS 2.1 and $\log K_{\mathrm{vow}}$ from

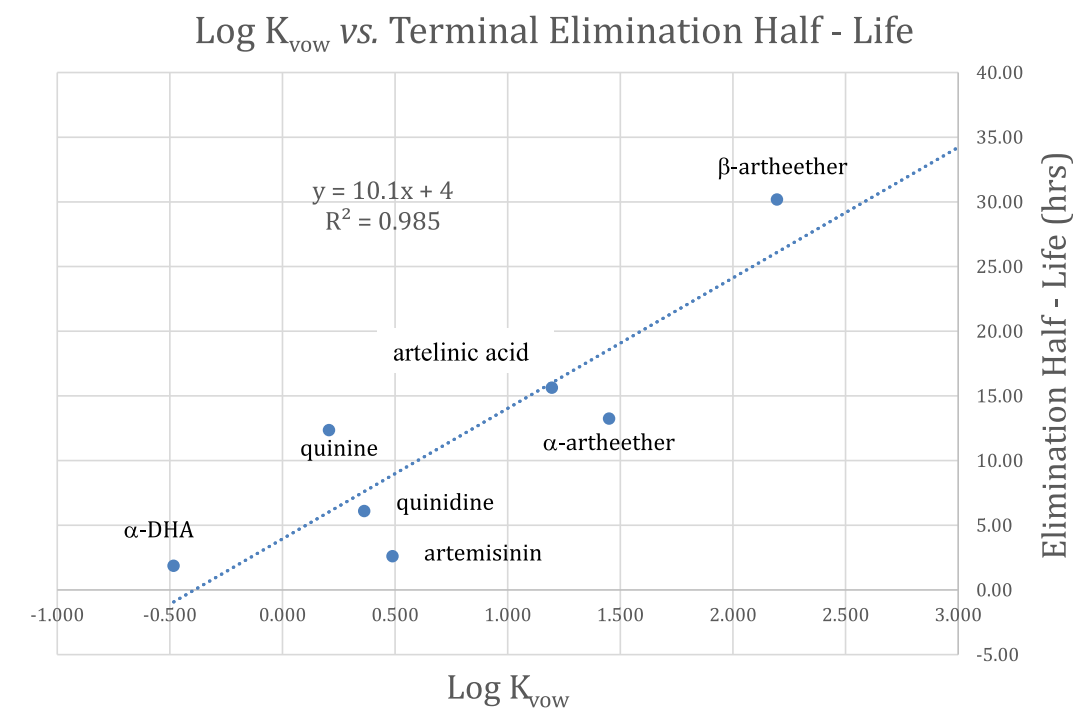

Figure 6. $\log K_{\text {vow }}$ from DFT-olive vs terminal elimination half-life. The best fit line includes lumefantrine $R$ and $S$ data points which are not shown to improve clarity. 
Table 6. Estimated Terminal Elimination Half-Life (h) for Experimental Artemisinin-Based Antimalarial Drugs Calculated from Linear Regression Results Presented in Table 5

\begin{tabular}{|c|c|c|c|c|c|}
\hline regression & $\beta$-DHA & Avery-14 & Avery-17 & $\mathrm{F}_{1}$-DHA & $\mathrm{F}_{2}$-DHA \\
\hline $\begin{array}{l}\log K_{\text {ow }} \\
\text { DFT-oct }\end{array}$ & $9 \pm 11$ & $48 \pm 11$ & $46 \pm 11$ & $32 \pm 11$ & $17 \pm 11$ \\
\hline $\begin{array}{l}\log K_{\text {vow }} \\
\text { DFT-olive }\end{array}$ & $6 \pm 9$ & $48 \pm 9$ & $45 \pm 9$ & $30 \pm 8$ & $10 \pm 9$ \\
\hline $\begin{array}{l}\log K_{\text {ow }} \\
\text { ALOGPS } \\
2.1^{a}\end{array}$ & $1 \pm 12$ & $53 \pm 12$ & $42 \pm 12$ & $22 \pm 12$ & $5 \pm 12$ \\
\hline $\begin{array}{l}\log K_{\text {ow }} \\
\text { ALOGPS } \\
2.1^{b}\end{array}$ & $0 \pm 21$ & $60 \pm 20$ & $49 \pm 20$ & $20 \pm 20$ & $12 \pm 19$ \\
\hline$\underset{\text { literature }}{\log K_{\text {ow }}}$ & $7 \pm 17$ & & & $31 \pm 16$ & $4 \pm 16$ \\
\hline
\end{tabular}

${ }^{a}$ SMILES strings translated by Online SMILES Translator and Structure File Generator https://cactus.nci.nih.gov/translate $/{ }^{67}$ from PDB files generated using GaussView software from optimized geometries. ${ }^{6}$ With optimized geometries from DFT in .mol2 format.

DFT-olive. See Table 7. The relationship between slope and intercept for $\log K_{\text {vow }}$ versus terminal $t_{1 / 2}$ is closer to what one

Table 7. Quinoline-Based Drugs and Pyronaridine Linear Least Square Results for Computed and Literature $\log K_{\text {ow }}$ vs Terminal Elimination Half-Life from the Literature ${ }^{a}$

\begin{tabular}{lcccc}
\multicolumn{1}{c}{ method } & slope & intercept & \multicolumn{1}{c}{$R^{2}$} & $F$ \\
$\log K_{\text {ow }}$ DFT-oct & $220 \pm 70$ & $-400 \pm 200$ & 0.712 & 14 \\
$\log K_{\text {vow }}$ DFT-olive & $180 \pm 70$ & $50 \pm 120$ & 0.598 & 7.4 \\
$\log K_{\text {ow }}$ ALOGPS 2.1 & $150 \pm 60$ & $-340 \pm 260$ & 0.57 & 6 \\
SMILES input & $210 \pm 40$ & $-550 \pm 160$ & 0.86 & 31 \\
$\log K_{\text {ow }}$ literature & & &
\end{tabular}

${ }^{a}$ Slopes and intercepts are given with their standard deviations.

would expect based on eq 6, in the Methods section, than for $\log K_{\mathrm{ow}}$ versus $t_{1 / 2}$. The certainty range for the slope, $110-250$ $\mathrm{h}$ is within the certainty range of the intercept multiplied by $\ln (10),-160$ to $390 \mathrm{~h}$. Calculated from the slope, $k_{\text {elim }}=0.014$ $\pm 0.012 \mathrm{~h}^{-1}$.

\section{DISCUSSION}

Outliers. The compounds found to be outliers need to be considered and explained in the context of the methods used. The DFT-oct transfer free energies, $\Delta G_{\text {ow }}$, for piperaquine, amodiaquine, and lumefantrine $R$ and $S$ enantiomers have errors in comparison with $\Delta G_{\text {ow }}$ calculated from experimental $\log K_{\text {ow }}$ outside the $99.9 \%$ certainty range of errors for the compounds considered in this work. Kolár et al. (2013) recognized two reasons for the failure of implicit solvent models including SMD: (1) problematic functional groups and (2) the molecule is large and flexible. ${ }^{21}$ Piperaquine, lumefantrine, and amodiaquine have similar functionality as the other compounds. Piperaquine and lumefantrine are the largest molecules studied here with 69 and 67 atoms, respectively, and with 6 and 9 rotatable ${ }^{21}$ bonds. Amodiaquine with 47 atoms and 5 rotatable bonds is structurally and functionally similar to desethyl amodiaquine with 41 atoms and 4 rotatable bonds, which falls within the certainty range indicating the larger error for amodiaquine to be due to its greater number of atoms and rotatable bonds. It may be tempting according to qualitative notions of conformational entropy to estimate improved $\Delta G_{\text {ow }}$ based on the number of known stable conformers but attempts to improve SMD through an ensemble of conformers has been shown to not lead to marked improvement. ${ }^{21}$ Perhaps this is because the inclusion of entropic effects in implicit solvent models is not well defined in terms of effects known to influence entropy in explicit solvation models. Although the outliers in comparison to $\Delta G_{\text {ow }}$ from DFT-oct give insight into the applicability of the SMD model, outliers in the linear regression of $\log K_{\text {ow }}$ versus terminal $t_{1 / 2}$ reflect differences in in vivo behavior of the drugs considered.

The outliers identified in the plots of $\log K_{\text {ow }}$ versus terminal elimination half-life served to identify two different linear relationships between $\log K_{\mathrm{ow}}$ and terminal $t_{1 / 2}$, one involving artemisinin drugs, amino alcohols (excluding mefloquine), and lumefantrine and the other involving 4-amino quinolines, mefloquine, and pyronaridine (see Figure 7). The trend lines shown in Figure 7 both include quinine and quinidine. To

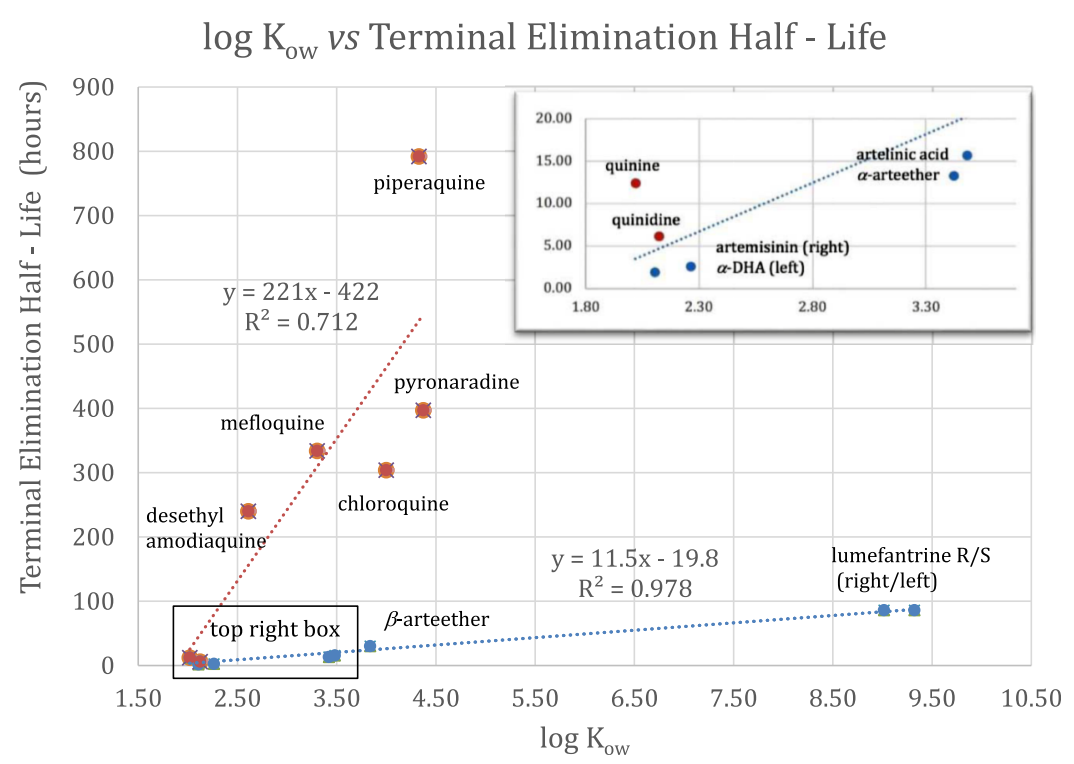

Figure 7. $\log K_{\mathrm{ow}}$ from DFT-oct vs terminal $t_{1 / 2}$ with two linear relationships shown identified by analysis of outliers. 
understand the difference between these two groups of compounds, it is useful to consider protein binding.

Differences in Protein Binding. The result that artemisinin and amino alcohol drugs trend together for log $K_{\text {ow }}$ versus terminal elimination half-life and quinoline drugs trend together may be due to differences in protein binding and, in the case of chloroquine, a larger distribution volume.

Piperaquine does not trend with artemisinin and amino alcohol drugs in $\log K_{\mathrm{ow}}$ versus terminal elimination half-life even when experimental $\log K_{\mathrm{ow}}$ values from the literature are used, but it is not an outlier when only quinoline drugs are compared. This may be due to the strong binding of quinoline compounds to $\alpha_{1}$-acid glycoprotein. Piperaquine is more than $99 \%$ bound by plasma proteins and has 8 times more binding to $\alpha_{1}$-acid glycoprotein than to human serum albumin. ${ }^{6}$ Lumefantrine, in contrast, binds primarily to high-density lipoproteins, HDL. ${ }^{69}$ Quinoline-based antimalarial drugs, amodiaquine, primaquine, tafenoquine, quinacrine, and mefloquine have high binding to $\alpha_{1}$-acid glycoprotein with binding constants in the range of $K_{\mathrm{a}}=10^{5}$ to $10^{6} .^{70}$ Interestingly, chloroquine, unlike the other 4-aminoquinoline drugs, is not found to bind significantly with $\alpha_{1}$-acid glycoprotein. $^{70}$ Ofori-Adjei et al. found $(+)$ and $(-)$ enantiomers of chloroquine to be 34.5 and $47.5 \%$ bound to $\alpha_{1}$-acid glycoprotein, respectively. ${ }^{71}$ Chloroquine's long terminal elimination half-life is not due to high plasma protein binding but to its large apparent distribution volume. ${ }^{72}$ Amino alcohols, quinine, and quinidine bind less strongly to $\alpha_{1}$-acid glycoprotein than mefloquine which is also an amino alcohol; quinine's $\alpha_{1}$-acid glycoprotein binding constant is $K_{\mathrm{a}}=9.12 \pm$ 0.73 , and it is $85-95 \%$ protein bound, whereas quinidine is $70-80 \%$ protein bound. ${ }^{73}$ Mefloquine is $98 \%$ protein bound in both patients and healthy volunteers, ${ }^{49}$ in accordance with its greater dipole moment and its strong binding to $\alpha_{1}$-acid glycoprotein. $^{70,74,75}$

Quinine and quinidine trend with both artemisinin drugs, including lumefantrine, and with other quinoline drugs perhaps due to their similar plasma protein binding to artemisininbased drugs. DHA protein binding is higher in plasma from patients $(93 \%)$, than in healthy volunteers ( $88 \%$ Vietnamese and $91 \%$ Caucasians). ${ }^{76,77}$ It is typical for $\alpha_{1}$-acid glycoprotein levels to be higher in malaria patients than healthy subjects. Artesunic acid is $73-81 \%$ protein bound in rats and humans. ${ }^{78}$ Artemether is $95-98 \%$ protein bound but only $33 \%$ bound to $\alpha_{1}$-acid glycoprotein. ${ }^{69}$ Terminal phase plasma concentrations of artemether are accompanied by its metabolite, DHA. ${ }^{56}$ This indicates that artemether's terminal elimination half-life not only depends on its lipophilicity and protein binding but its chemical conversion to DHA. Arteether was found to be 73.4$81.8 \%$ in 11 healthy male subjects with about 20 times greater binding affinity to $\alpha_{1}$-acid glycoprotein than to albumin. ${ }^{79}$

When $\log K_{\mathrm{ow}}$ is plotted against elimination half-life, lumefantrine, quinine, quinidine, and the artemisinin-based drugs trend together. This is likely due to stronger binding of the 4-aminoquinoline drugs primarily to $\alpha_{1}$-acid glycoprotein and, in the case of chloroquine, large distribution volume. Lumefantrine, although highly fat soluble, does not trend with the 4-aminoquinoline drugs because it binds primarily to highdensity lipoproteins.

Terminal Elimination Half-Life Versus log $K_{\text {vow }}$. The linear relationship between terminal elimination half-life and $\log K_{\text {vow }}$ for artemisinin drugs, quinine and quinidine, and lumefantrine, is particularly strong, $R^{2}=0.985$ and $F=467$ (see Table 5). The slope and intercept follow the relationship expected according to the simple kinetic model presented in the Methods section, intercept $\times \ln (10)=$ slope, and this is not the case for the other $\log K_{\mathrm{ow}}$ versus $t_{1 / 2}$ regressions in Table 5 . An elimination rate constant, $k_{\text {elim }}$ in the context of this model can be computed based on the slope and/or intercept. Although all of the slopes in Table 5 make similar predictions for $k_{\text {elim }}$ the plot of $\log K_{\text {vow }}$ and $t_{1 / 2}$ is the only one with an intercept that seems meaningful. Perhaps the strong linear relationship and agreement between the intercept and pharmacokinetic model are evidence that predictions made regarding solubility in olive oil, which is a biological fat, are more relevant for comparison to in vivo properties, such as terminal elimination half-life. The results are analogous for log $K_{\text {vow }}$ and $t_{1 / 2}$ for the quinoline compounds but the linear fit is much weaker, so the computed $k_{\text {elim }}$ has a much wider certainty range. Equation 6 and the simple pharmacokinetic model from which it is derived indicated two contributing factors to terminal half-life, the hydrophobic/hydrophilic partitioning of the drug and the rate of elimination of the drug from aqueous environment. The rate constant, $k_{\text {elim }}$ is for the elimination from aqueous environment. It is predicted to be smaller for quinoline drugs, and this may be due to different renal and hepatic elimination processes and their greater plasma protein binding in particular to $\alpha_{1}$-acid glycoprotein which does not have a strong linear correlation with lipophilicity. ${ }^{75}$

Lumefantrine, $\log K_{\mathrm{ow}}$, and Bioavailability. There is a wide range of terminal elimination half-life values reported for lumefantrine in the literature. ${ }^{80}$ Lefèvre and Thomsen (1999) find the lumefantrine terminal elimination half-life to be $71.3 \mathrm{~h}$ (fed) and $35.1 \mathrm{~h}$ (fasted) and that lumefantrine's bioavailability increases 16 times when it is administered in conjunction with food. ${ }^{64}$ Piperaquine by contrast shows little change in terminal elimination half-life depending on whether subjects are fed or fasted. ${ }^{81}$ Lumefantrine's high predicted $\log K_{\mathrm{ow}}$ and $\log K_{\mathrm{vow}}$ are suggestive of lumefantrine's solubility with dietary fats which helps to increase its terminal elimination half-life and strong binding to HDL proteins.

Diastereomers. The diastereomers $\alpha$ - and $\beta$-arteether have different physical and pharmacokinetic properties and slightly different antimalarial activity. To our knowledge, different log $K_{\text {ow }}$ values for $\alpha$ - and $\beta$-arteether are not available in the literature. The greater predicted $\log K_{\mathrm{ow}}$ for $\beta$-arteether compared to $\alpha$-arteether, 3.84 compared to 3.42 (Table 3), is consistent with the terminal elimination half-life of $31.17 \mathrm{~h}$ for $\beta$-arteether and $13.24 \mathrm{~h}$ for $\alpha$-arteether. ${ }^{57}$ The greater lipophilicity of $\beta$-arteether is understandable according to its smaller dipole moment, $1.79 \mathrm{D}$ compared to $2.84 \mathrm{D}$ for $\alpha$ arteether, both computed using DFT. This difference in dipole moment can be understood according to the difference in geometry. The $\mathrm{C}_{10}$ ethyl ether in $\beta$-arteether points in the opposite direction to the endoperoxide partially canceling the molecular dipole moment (see Figure 8). The influence between the orientation of $\mathrm{C}_{10}$ substituents with respect to the endoperoxide group in artemisinin drugs and dipole moment and the correlation of this with greater neurotoxicity with smaller dipole moment was pointed out by Bhattacharjee and Karle (1999). ${ }^{82}$

The $\alpha$ - and $\beta$-diastereomers of arteether have similar antimalarial activity against strains of Plasmodium berghei in rodents but slightly different activity depending on the strain with $\beta$-arteether being slightly more active. ${ }^{83} \beta$-arteether is also found to be slightly more active against Plasmodium cynomolgi 


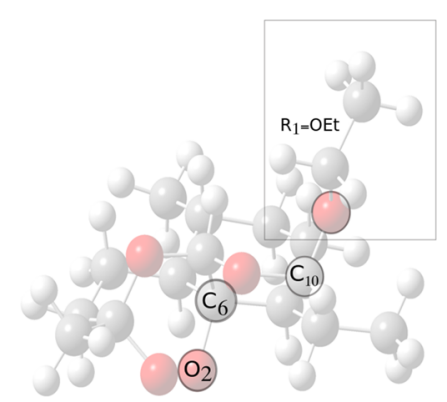

Figure 8. $\beta$-arteether DFT-optimized geometry. $\mathrm{C}_{6}-\mathrm{O}_{2}$ endoperoxide and $\mathrm{C}_{10}$-OEt bond dipoles point in opposite directions partially cancelling the molecular dipole moment. Atom numbering is the same as in Figure 2.

malaria in monkeys, whereas $\beta$-arteether and $\alpha / \beta$-arteether (30:70) mixture have similar activity against $P$. falciparum malaria in humans and similar toxic side effects during therapy. ${ }^{84}$ The slightly greater activity of $\beta$-arteether may be due to its greater lipophilicity and smaller dipole moment allowing it to pass through the erythrocyte cell membrane more effectively, assuming it has not already been converted to its metabolite, DHA. ${ }^{19}$

DHA is the active metabolite of some of the most widely used artemisinin-based antimalarial drugs. Artesunic acid is converted to the active metabolite, DHA most quickly followed by artemether and then arteether. The pharmacokinetics, antimalarial activity, and toxicity of DHA are therefore relevant to the behavior of the most widely used artemisinin derivatives. Diastereomers, $\alpha$ - and $\beta$-DHA, interconvert in solution and so, the properties of each are important to consider. Haynes et al. (2006) report $\log K_{\text {ow }}$ of the two DHA epimers in solution to be 2.35 and 2.73 but do not specify the respective values for $\alpha$ and $\beta$-DHA. ${ }^{14}$ According to DFT-oct, $\log K_{\mathrm{ow}}=2.11$ for $\alpha$-DHA and 2.53 for $\beta$-DHA, which is evidence that the more lipophilic $\log K_{\text {ow }}$ found by Haynes et al. corresponds to $\beta$-DHA, consistent with its smaller dipole moment, $1.582 \mathrm{D}$, compared to $3.147 \mathrm{D}$ for $\alpha$-DHA, according to DFT.

DHA has a labile stereocenter at $\mathrm{C}_{10}$. D'Acquarica et al. (2010) report that solid-state DHA consists of $\beta$-DHA only, whereas $\alpha$ - and $\beta$-DHA interconversion rates in solution depend on buffer, $\mathrm{pH}$, and solvent polarity. ${ }^{85}$ They report that the Gibbs free energy of activation for HPLC on-column epimerization from $\alpha$-DHA to $\beta$-DHA, $\Delta G_{\alpha \rightarrow \beta}^{\neq, \text {, }}$, is slightly higher than the reverse, $\Delta G_{\beta \rightarrow \alpha}^{\neq, \mathrm{o}}$, based on van't Hoff plots and find the difference to be entropic which they believe suggests a ring-opening mechanism. ${ }^{85}$ These relative free energies of activation imply higher concentrations of $\alpha$-DHA than $\beta$-DHA at equilibrium, which is found to be the case in $50 \% \mathrm{v} / \mathrm{v}$ ethanol/water solution and $50 \% \mathrm{v} / \mathrm{v}$ acetonitrile/water solution. ${ }^{76}$ Batty et al. (2004) found plasma $\alpha$-DHA/ $\beta$-DHA ratios in vivo to favor $\alpha$-DHA of $6.3 \pm 0.9$ in patients with falciparum malaria, $6.9 \pm 0.8$ in patients with vivax malaria, 6.9 \pm 0.6 in healthy Vietnamese volunteers, and $5.4 \pm 0.8$ in healthy Caucasian volunteers. ${ }^{76}$ The greater dipole moment of $\alpha$-DHA may imply it to be more strongly bound to $\alpha_{1}$-acid glycoprotein. ${ }^{75}$ If $\alpha$-DHA has higher protein binding, more unbound $\alpha$-DHA would be formed from unbound $\beta$-DHA to maintain the equilibrium unbound in plasma according to Le Chatelier's principle and increase the overall ratio of $\alpha$ to $\beta$ DHA in plasma.
Single-point computations based on the in vacuo optimized geometries of $\alpha$ - and $\beta$-DHA predict $\beta$-DHA to be more stable in the gas phase, in water, in 1-octanol, and in olive oil. To test the effect of geometrical relaxation in solution and thermal enthalpies and entropies on relative stability, $\alpha$ - and $\beta$-DHA geometries were optimized in each solvent and frequency calculations performed in order to identify a minimum in energy with all positive real vibrational frequencies and to yield thermal corrections to enthalpy as well as entropy in each solvent. The thermally corrected results which included entropic effects correctly predicted the greater thermodynamic stability of $\alpha$-DHA in water with $\Delta G_{\beta \rightarrow \alpha}^{\circ}=-0.344 \mathrm{~kJ} \mathrm{~mol}^{-1}$, $\Delta H_{\beta \rightarrow \alpha}^{\mathrm{o}}=0.869 \mathrm{~kJ} \mathrm{~mol}^{-1}$, and $\Delta S_{\beta \rightarrow \alpha}^{\mathrm{o}}=4.07 \mathrm{~J} \mathrm{~mol}^{-1} \mathrm{~K}^{-1}$ at $298.15 \mathrm{~K}$. The greater entropy at $298.15 \mathrm{~K}$ of $\alpha$-DHA in water than $\beta$-DHA outweighs the more negative enthalpy of $\beta$-DHA, which is not completely overcome by the fact that $\alpha$-DHA is more polar. These computations also give heat capacities, $C_{V}$, and with them $\Delta G_{\beta \rightarrow \alpha}^{\mathrm{o}}, \Delta H_{\beta \rightarrow \alpha}^{\mathrm{o}}$, and $\Delta S_{\beta \rightarrow \alpha}^{\mathrm{o}}$ can be approximated at $310.15 \mathrm{~K}$ yielding $\Delta G_{\beta \rightarrow \alpha}^{\mathrm{o}}=-0.393 \mathrm{~kJ}$ $\mathrm{mol}^{-1}, \Delta H_{\beta \rightarrow \alpha}^{\mathrm{o}}=0.880 \mathrm{~kJ} \mathrm{~mol}^{-1}$, and $\Delta S_{\beta \rightarrow \alpha}^{\mathrm{o}}=4.103 \mathrm{~J} \mathrm{~mol}^{-1}$ $\mathrm{K}^{-1}$. The Boltzmann population of $\alpha$-DHA in water at 310.15 $\mathrm{K}$ is predicted to be $54 \%$ giving $\alpha$-DHA $/ \beta$-DHA ratio of 1.17 , correctly favoring but also underestimating the apparent greater relative stability of $\alpha$-DHA in an aqueous environment. The greater ratio of $\alpha$ - to $\beta$-DHA in plasma may also be increased by stronger binding of $\alpha$-DHA to $\alpha_{1}$-acid glycoprotein as discussed in the previous paragraph. Similar computations with 1-octanol and olive oil as the solvents show greater computed entropy of $\alpha$-DHA than $\beta$-DHA in water compared to these other solvents, which is due to lowfrequency vibrations involving the $-\mathrm{OH}$ group and DHA fused ring systems and lower computed enthalpy presumably due to stronger dipole-dipole interactions with the greater polarity of $\alpha$-DHA. The difference in predicted entropy is less in 1octanol and in olive oil, $\Delta G_{\beta \rightarrow \alpha}^{\mathrm{o}}=2.83, \Delta H_{\beta \rightarrow \alpha}^{\mathrm{o}}=3.76 \mathrm{~kJ}$ $\mathrm{mol}^{-1}, \Delta S_{\beta \rightarrow \alpha}^{\mathrm{o}}=3.13 \mathrm{~J} \mathrm{~mol}^{-1} \mathrm{~K}^{-1}$, in 1-octanol and $\Delta G_{\beta \rightarrow \alpha}^{\mathrm{o}}=$ $5.12, \Delta H_{\beta \rightarrow \alpha}^{\mathrm{o}}=5.87 \mathrm{~kJ} \mathrm{~mol}^{-1}$ and $\Delta S_{\beta \rightarrow \alpha}^{\circ}=2.45 \mathrm{~J} \mathrm{~mol}^{-1} \mathrm{~K}^{-1}$ in olive oil. $\beta$-DHA is predicted to be more stable than $\alpha$-DHA in octanol and olive oil at $310.15 \mathrm{~K}$.

Quinine and quinidine, also diastereomers, show difference in antimalarial activity; quinidine shows twice the antimalarial activity as quinine against $P$. falciparum. ${ }^{19}$ Inspection of Figure 5 reveals that they differ from being mirror images only in the position of the quinuclidine vinyl group. Warhurst et al. (2003) report $\log K_{\mathrm{ow}}$ values of 3.17 and 2.84 for quinine and quinidine, respectively, but also cite Tsai et al. (1993) as giving 2.64 for quinine and 2.88 for quinidine. Our computations agree with the latter predicting $\log K_{\mathrm{ow}}$ to be greater for quinidine than for quinine. The shorter terminal elimination half-life for quinidine, that is, $6.09 \mathrm{~h}$ compared to $12.34 \mathrm{~h}$ for quinine then does not follow the general trend of increased elimination half-life with increased lipophilicity. The longer elimination half-life of quinine can be explained by the greater protein binding of quinine (85-95\%) compared to quinidine $(70-80 \%) .{ }^{73}$ If quinidine is indeed less lipophilic than quinine, it is interesting that it has less protein binding. Urien et al. (1995) in their study of the binding of eight drugs to $\alpha_{1}$-acid glycoprotein found that $\Delta G_{\text {bind }}$ does not have a strong correlation with physicochemical parameters including log $K_{\text {ow }}{ }^{75}$ On considering $\Delta H_{\text {bind }}$ and $T \Delta S_{\text {bind }}$ independently, they found strong linear relationships of each with $\log P_{\text {oct-hep }}=\log$ $K_{\mathrm{ow}}-\log K_{\mathrm{hw}}$, where $K_{\mathrm{hw}}$ is the heptane-water partition coefficient. ${ }^{75} \Delta H_{\text {bind }}$ becomes more negative with increased log 
Table 8. Transfer Entropies $\left(\mathrm{J} \mathrm{mol}^{-1} \mathrm{~K}^{-1}\right)$, Enthalpies $\left(\mathrm{kJ} \mathrm{mol}^{-1}\right)$, Heat Capacities $\left(\mathrm{kJ} \mathrm{mol}{ }^{-1} \mathrm{~K}^{-1}\right), \log K_{\mathrm{ow}}$, and log $K_{\mathrm{vow}}$ of Quinine and Quinidine at 298.15 $\mathrm{K}^{a}$

\begin{tabular}{|c|c|c|c|c|c|c|c|c|}
\hline$T=298.15 \mathrm{~K}$ & $\Delta S_{\text {ow }}^{o}$ & $\Delta S_{\mathrm{vow}}^{\mathrm{o}}$ & $\Delta H_{\mathrm{ow}}^{\mathrm{o}}$ & $\Delta H_{\mathrm{vow}}^{\mathrm{o}}$ & $\Delta C_{\mathrm{v}, \mathrm{ow}}^{\mathrm{o}}$ & $\Delta C_{\mathrm{v}, \text { vow }}^{\mathrm{o}}$ & $\log K_{\text {ow }}$ & $\log K_{\text {vow }}$ \\
\hline quinine & -0.623 & -5.028 & -10.197 & 1.376 & -0.385 & -0.946 & 1.75 & -0.503 \\
\hline quinidine & 1.331 & 7.242 & -10.610 & 0.635 & -0.2 .01 & -0.121 & 1.94 & 0.267 \\
\hline$T=310.15 \mathrm{~K}$ & $\Delta S_{\mathrm{ow}}^{\mathrm{o}}$ & $\Delta S_{\mathrm{vow}}^{\mathrm{o}}$ & $\Delta H_{\mathrm{ow}}^{\mathrm{o}}$ & $\Delta H_{\mathrm{vow}}^{\mathrm{o}}$ & $\Delta G_{\mathrm{ow}}^{\mathrm{o}}$ & $\Delta G_{\mathrm{vow}}^{\mathrm{o}}$ & $\log K_{\text {ow }}$ & $\log K_{\mathrm{vow}}$ \\
\hline quinine & -0.639 & -5.058 & -10.202 & -1.364 & -10.004 & 2.933 & 1.68 & -0.494 \\
\hline quinidine & 1.581 & 7.238 & -10.612 & 0.634 & -11.103 & -1.611 & 1.87 & 0.271 \\
\hline
\end{tabular}

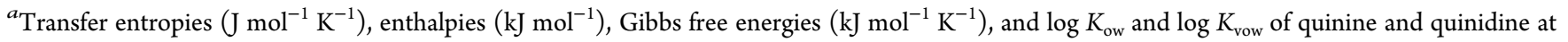
$310.15 \mathrm{~K}$.

$P_{\text {oct-hep }}$ and $-T \Delta S_{\text {bind }}$ less negative. ${ }^{75}$ The $\log P_{\text {oct-hep }}$ parameter is a measure of dipole-dipole interaction between the solute and octanol. ${ }^{75}$ The greater protein binding of quinine compared to quinidine may be due to greater dipole moment, that is $2.74 \mathrm{D}$ for quinine compared to $2.46 \mathrm{D}$ for quinidine both in vacuo according to DFT. The computed log $P_{\text {oct-hep }}$ values also show the same trend, $\log P_{\text {oct-hep }}=2.74$ for quinine and 2.46 for quinidine, coincidentally the same magnitudes as their dipole moments. This is for the most stable conformer of each which is also the most lipophilic. Given that quinine and quinidine have nearly equal $\% \beta$-haemitin inhibition, perhaps quinidine's greater antimalarial activity is due to its greater lipophilicity leading to better penetration through the erythrocyte cell membrane. ${ }^{19}$

Given the structural similarity between quinine and quinidine, the differences in their properties are quite interesting. Although one might expect the difference in position of the quinuclidine vinyl group to cause differences in rotational accessibility of the conformers, Zaera et al. (2009) found little difference in the energy and accessibility of cinchonidine and cinchonine conformers formed by rotations around $\tau_{1}$ and $\tau_{2}$ (Table S2) and attribute solubility differences between these and analogous cinchona compounds such as quinidine and quinine to differences in vibrational entropy mostly accounted for in the most stable conformer of each compound and resulting from the change in center of mass with different position of this vinyl substituent. ${ }^{20}$ The difference in computed entropies they found showed agreement with the temperature dependence of their experimentally determined solubilities. Hoping to clarify the relative lipophilicities of quinine and quinidine and to test the effects of solvent specific geometry relaxation in each solvent and differences in entropy and thermally corrected enthalpy, quinine and quinidine geometries were optimized in water, 1-octanol, and olive oil and vibrational frequency analysis was performed, confirming that a minimum in energy had been found and yielding thermally corrected free energies, enthalpies, entropies, and heat capacities at $298.15 \mathrm{~K}$ and allowing those at $310.15 \mathrm{~K}$ to be predicted based on the computed heat capacities. Results are given in Table 8 .

The increase in entropy for quinidine going from water to 1octanol or olive oil while the transfer entropy of quinine is negative is interesting and results from differences in vibrational entropy in each solvent. The predicted effects at 298.15 and $310.15 \mathrm{~K}$ do not change the trend in lipophilicity. With the effects of thermal enthalpies and entropies included, both compounds are predicted to increase relative solubility in water with increased temperature. Quinidine is still predicted to be more lipophilic according to its more positive $\log K_{\text {ow }}$ and $\log K_{\text {vow }}$ values presented in Table 8 .
Estimates of Terminal Elimination Half-Life. The strong linear relationships found between $\log K_{\mathrm{ow}}$ and terminal elimination half-life indicate the close relationship between terminal $t_{1 / 2}$ and relative thermodynamic stability in octanol or olive oil compared to water, $\Delta G_{\mathrm{ow}}^{\mathrm{o}}$ or $\Delta G_{\mathrm{vow}}^{\mathrm{o}}$, for drugs that trend together. Assuming similar plasma protein binding, rates of metabolism, and relationships between distribution volume and clearance for structurally similar drugs, these linear relationships allow estimation of terminal elimination half-life for experimental antimalarial drugs. As mentioned above, the predominant DHA diastereomer in plasma was found to be $\alpha$ DHA. ${ }^{76}$ The DHA terminal half-life of $1.86 \mathrm{~h}$ given by Jitamala et al. $(2015)^{55}$ may reflect primarily the properties of $\alpha$-DHA and the predicted $\beta$-DHA half-life of $6 \mathrm{~h}$ may be of interest. The smaller dipole moment and greater lipophilicity of $\beta$-DHA may allow it easier penetration through the erythrocyte cell membrane and greater antimalarial activity at the same time as greater neurotoxicity. The predicted higher $\log K_{\mathrm{ow}}$ for $\beta$ arteether than $\alpha$-arteether matches $\beta$-arteether's longer terminal elimination half-life.

Avery et al. (2002) report terminal half-life in rats of Avery17 to be $73 \mathrm{~min}$ and that for Avery-14 to be less than this. ${ }^{12}$ Using $\log K_{\mathrm{ow}}=5.69$ from Table 3 and $t_{1 / 2}=1.22 \mathrm{~h}$ in eq 6 from Sarver et al. $(1997)^{39}$ predicts a half-life of $5.72 \mathrm{~h}$ in humans, which is surprisingly low, given the alkyl/aryl substitution of these compounds and their high lipophilicity. An abnormally low terminal elimination half-life could be explained based on abnormally low volume of distribution, $V_{\mathrm{d}, \mathrm{ss}, \mathrm{u}}$. Avery et al. suggest that the lower apparent terminal half-life of Avery-14 compared to Avery-17 may be due to structural features of these compounds but also suggest that the cause may be lower plasma concentrations for Avery-14 that reflect a distribution phase rather than a true terminal phase. ${ }^{12}$ Computed dipole moments for Avery-14 and Avery17 are 4.41 and $4.86 \mathrm{D}$, respectively. Perhaps analogous to quine and quinidine, Avery-17 has greater $\alpha_{1}$-acid glycoprotein binding and longer terminal $t_{1 / 2}$ compared to Avery-14 which is more lipophilic. The greater potency of Avery-17, according to our optimized geometries may be explained by a slightly more obstructed endoperoxide group in Avery-14. The results here suggest that if factors determining pharmacokinetics for Avery-14 and Avery-17 are similar to other artemisinin drugs, they have considerably longer terminal elimination half-life. Avery-14 and Avery-17 are predicted to be highly lipophilic in agreement with their large predicted $\log K_{\mathrm{ow}}$ values given in Table 3. Avery et al. note that these compounds have high potency but low bioavailability due to poor solubility. The predicted terminal elimination half-lives of 48 and $45 \mathrm{~h}$, respectively, for Avery-14 and Avery-17, if accurate, may be in an appropriate range to counter the altered life cycle of resistant strains and perhaps would be less likely to trigger 
resistance and neurotoxicity if they do not have DHA as an active metabolite.

$\mathrm{F}_{1}$-DHA is found to have higher lipophilicity than $\mathrm{F}_{2}$-DHA in agreement with their log $K_{\text {oct:Ringer }}$ but perhaps the estimated $\log K_{\text {ow }}$ values in Table 3 allow them to be considered in a consistent context with other antimalarial drugs. The $\mathrm{C}_{10}$ fluoroalkyl group of $\mathrm{F}_{1}$-DHA presents an obstacle to transfer across the intestinal lining, so the estimated terminal elimination half-life given in Table 6 is likely not of much interest. The predicted terminal elimination half-life of $\mathrm{F}_{2}$ DHA, which is $10 \mathrm{~h}$, is similar to those for DHA, artemether, and arteether, drugs with greater possible neurotoxicity and perhaps greater vulnerability to artemisinin-resistant malaria because their active metabolite, DHA, may trigger the dormant ring stage.

\section{SUMMARY AND CONCLUSIONS}

The results here show that quantum chemical $\log K_{\text {ow }}$ values from DFT with the SMD implicit solvent model have a strong linear relationship with the terminal elimination half-life for drugs used in antimalarial ACT therapies and experimental antimalarial drugs. This relationship follows a simple pharmacokinetic model, and the results modeling olive oil as a solvent match the predicted relationship between the slope and intercept, which is perhaps an indication that olive oil as a biological fat is more appropriate than 1-octanol in comparison to these in vivo drug properties. The predicted $\log K_{\mathrm{ow}}$ values for 21 antimalarial drugs based on computed water to 1octanol underestimate the relative stability in 1-octanol by a mean of value of $2.3 \mathrm{~kJ} \mathrm{~mol}^{-1}$ and show a mean unsigned error of $3.7 \mathrm{~kJ} \mathrm{~mol}^{-1}$, which is in good agreement with the literature mean unsigned error values for compounds with similar functionalities. Errors are larger for larger molecules with more rotatable bonds consistent with the work of Kolár et al. $(2013) .{ }^{21}$ In plots of $\log K_{\mathrm{ow}}$ versus terminal $t_{1 / 2}$, artemisinin and amino alcohol-based drugs were found to trend together and 4-aminoquinoline compounds are found to trend with mefloquine and pyronaridine, consistent with the protein binding of these different families of compounds. The linear fit with olive oil as the modeled solvent allows terminal elimination half-lives to be estimated for $\beta$-DHA and five experimental antimalarial drugs. An advantage of the methodology used here is that the physical properties of compounds with subtle but important geometric differences can be distinguished as demonstrated by the three sets of diastereomers studied. Computed differences between $\alpha$ and $\beta$ arteether correlate with their different $t_{1 / 2}$ and allow for interpretation of their slightly different antimalarial activity. Computed lipophilicities for $\alpha$ and $\beta$-DHA allow experimentally determined $\log K_{\mathrm{ow}}$ to be assigned for them. The $\alpha$ diastereomer of DHA is found to be favored in aqueous media, and this is understood in terms of its greater entropy in water. Solubilities of quinine and quinidine are also found to be sensitive thermal effects of thermal enthalpy and entropy in different solvents. The experimental antimalarial drugs studied in this work were previously designed for longer $t_{1 / 2}$ and lower neurotoxicity. It is suggested based on their estimated terminal elimination half-lives that their properties or properties of similar drugs may also be conducive to addressing the problem of ACT-resistant strains based on the resistant strains' altered developmental stages.

\section{ASSOCIATED CONTENT}

\section{Supporting Information}

The Supporting Information is available free of charge at https://pubs.acs.org/doi/10.1021/acsomega.9b04140.

Geometrical parameters for artemisinin, DHA, arteether, quinine, and quinidine and plots of $\log K_{\mathrm{ow}}$ versus terminal $t_{1 / 2}$ including lumefantrine data points; geometrical parameters for the endoperoxide bridge in artemisinin-based structures; dihedral angles $\tau_{1}$ $\mathrm{C}_{3} \mathrm{C}_{4} \mathrm{C}_{9} \mathrm{C}_{8}, \quad \tau_{2} \quad \mathrm{C}_{4} \mathrm{C}_{9} \mathrm{C}_{8} \mathrm{C}_{1}, \quad \tau_{3} \quad \mathrm{~N}_{1} \mathrm{C}_{8} \mathrm{C}_{9} \mathrm{O}$, and $\tau_{4}$ $\mathrm{C}_{9} \mathrm{C}_{8} \mathrm{OH}$ as indicators of correct lowest energy conformations of quinine and quinidine; best-fit line for the DFT-olive results compared to terminal elimination half-life; best-fit lines for DFT-olive, DFToct; and ALOGPS 2.1 (SMILES) results, including lumefantrine data points for each (PDF)

\section{AUTHOR INFORMATION}

\section{Corresponding Author}

Joseph D. Alia - Division of Science and Mathematics, University of Minnesota Morris, Morris, Minnesota 56267, United States; ○ orcid.org/0000-0001-8998-7523; Phone: (320) 589-6345; Email: aliaj@morris.umn.edu

\section{Authors}

Sheila Karl - Division of Science and Mathematics, University of Minnesota Morris, Morris, Minnesota 56267, United States

Tyler D. Kelly - Division of Science and Mathematics, University of Minnesota Morris, Morris, Minnesota 56267, United States

Complete contact information is available at: https://pubs.acs.org/10.1021/acsomega.9b04140

\section{Notes}

The authors declare no competing financial interest.

\section{ACKNOWLEDGMENTS}

The authors are grateful to the Louis Stokes North Star STEM Alliance for funding that supported student participation in this research and to the University of Minnesota Morris Chemistry Discipline, Science and Math Division, and Dean's Office for the sabbatical during which a major part of this work was completed. We also thank Gaussian technical support for help with use of SMD to model 1-octanol and olive oil solvation properties.

\section{REFERENCES}

(1) World Health Organization. World Malaria Report 2018; World Health Organization, 2018, License: CC BY-NC-SA 3.0 IGO.

(2) Haldar, K.; Bhattacharjee, S.; Safeukui, I. Drug resistance in Plasmodium. Nat. Rev. Microbiol. 2018, 16, 156.

(3) Youdom, S. W.; Chiabi, A.; Basco, L. K. Monitoring the Efficacy and Safety of Artemisinin-Based Combination Therapies: A Review and Network Meta-analysis of Antimalarial Therapeutic Efficacy Trials in Cameroon. Drugs R\&D 2019, 19, 1-14.

(4) Muller, O.; Lu, G. Y.; von Seidlein, L. Geographic expansion of artemisinin resistance. J. Trav. Med. 2019, 26, taz030.

(5) Hott, A.; Casandra, D.; Sparks, K. N.; Morton, L. C.; Castanares, G.-G.; Rutter, A.; Kyle, D. E. Artemisinin-Resistant P. Falciparum Parasites Exhibit Altered Patterns of Development in Infected Erythrocytes. Antimicrob. Agents Chemother. 2015, 59, 3156-3167.

(6) Chandra, R.; Kumar, S.; Puri, S. K. Buthionine sulfoximine increases the efficacy of arteether antimalarial activity in arteether- 
resistant Plasmodium vinckei by glutathione depletion. Malar. World J., www.malariaworld.org 2015, 6.

(7) Hastings, I. M.; Hodel, E. M. Pharmacological considerations in the design of anti-malarial drug combination therapies - is matching half-lives enough? Malar. J. 2014, 13, 62.

(8) Hastings, I. M.; Hodel, E. M.; Kay, K., Quantifying the pharmacology of antimalarial drug combination therapy. Sci. Rep. 2016, 6. DOI: $10.1038 / \operatorname{srep} 32762$

(9) Hodel, E. M.; Kay, K.; Hastings, I. M. Incorporating StageSpecific Drug Action into Pharmacological Modeling of Antimalarial Drug Treatment. Antimicrob. Agents Chemother. 2016, 60, 27472756.

(10) Li, Q.; Pybus, B., Phharmacokinetic and Pharmacodynamic Profiles of Rapid- and Slow-Acting Antimalarial Drugs. Malaria. Open access peer-reviewed chapter-ONLINE FIRST; IntechOpen, 2019.

(11) Wesche, D. L.; Decoster, M. A.; Tortella, F. C.; Brewer, T. G. Neurotoxicity of Artemisinin Analogs in-Vitro. Antimicrob. Agents Chemother. 1994, 38, 1813-1819.

(12) Avery, M. A.; Alvim-Gaston, M.; Vroman, J. A.; Wu, B.; Ager, A.; Peters, W.; Robinson, B. L.; Charman, W. Structure-activity relationships of the antimalarial agent artemisinin. 7. Direct modification of $(+)$-artemisinin and in vivo antimalarial screening of new, potential preclinical antimalarial candidates. J. Med. Chem. 2002, 45, 4321-4335.

(13) Bigucci, F.; Kamsu-Kom, T.; Cholet, C.; Besnard, M.; BonnetDelpon, D.; Ponchel, G. Transport of fluoroalkyl dihydroartemisinin derivatives across rat intestinal tissue. J. Pharm. Pharmacol. 2008, 60, 163-169.

(14) Haynes, R. K.; Fugmann, B.; Stetter, J.; Rieckmann, K.; Heilmann, H.-D.; Chan, H.-W.; Cheung, M.-K.; Lam, W.-L.; Wong, H.-N.; Croft, S. L.; Vivas, L.; Rattray, L.; Stewart, L.; Peters, W.; Robinson, B. L.; Edstein, M. D.; Kotecka, B.; Kyle, D. E.; Beckermann, B.; Gerisch, M.; Radtke, M.; Schmuck, G.; Steinke, W.; Wollborn, U.; Schmeer, K.; Römer, A. Artemisone - A highly active antimalarial drug of the artemisinin class. Angew. Chem. Int. Ed. 2006, 45, 2082-2088.

(15) Chou, J. T.; Jurs, P. C. Computer-Assisted Computation of Partition-Coefficients from Molecular-Structures Using Fragment Constants. J. Chem. Inf. Comput. Sci. 1979, 19, 172-178.

(16) VCCLAB, Virtural Computational Chemistry Laboratory. 2005, http://www.vcclab.org (accessed September and October 2019).

(17) Tetko, I. V.; Gasteiger, J.; Todeschini, R.; Mauri, A.; Livingstone, D.; Ertl, P.; Palyulin, V. A.; Radchenko, E. V.; Zefirov, N. S.; Makarenko, A. S.; Tanchuk, V. Y.; Prokopenko, V. V. Virtual computational chemistry laboratory - design and description. $J$. Comput.-Aided Mol. Des. 2005, 19, 453-463.

(18) Tetko, I. V.; Tanchuk, V. Y. Application of associative neural networks for prediction of lipophilicity in ALOGPS 2.1 program. J. Chem. Inf. Comput. Sci. 2002, 42, 1136-1145.

(19) Warhurst, D. C.; Craig, J. C.; Adagu, I. S.; Meyer, D. J.; Lee, S. $\mathrm{Y}$. The relationship of physico-chemical properties and structure to the differential antiplasmodial activity of the cinchona alkaloids. Malar. J. 2003, 2, 26.

(20) Lai, J.; Ma, Z.; Mink, L.; Mueller, L. J.; Zaera, F. Influence of Peripheral Groups on the Physical and Chemical Behavior of Cinchona Alkaloids. J. Phys. Chem. B 2009, 113, 11696-11701.

(21) Kolár̆, M.; Fanfrlik, J.; Lepsik, M.; Forti, F.; Luque, F. J.; Hobza, P. Assessing the Accuracy and Performance of Implicit Solvent Models for Drug Molecules: Conformational Ensemble Approaches. J. Phys. Chem. B 2013, 117, 5950-5962.

(22) Becke, A. D. Density-Functional Thermochemistry .3. The Role of Exact Exchange. J. Chem. Phys. 1993, 98, 5648-5652.

(23) Lee, C.; Yang, W.; Parr, R. G. Development of the ColleSalvetti Correlation-Energy Formula into a Functional of the Electron-Density. Phys. Rev. B 1988, 37, 785-789.

(24) Vosko, S. H.; Wilk, L.; Nusair, M. Accurate Spin-Dependent Electron Liquid Correlation Energies for Local Spin-Density Calculations - a Critical Analysis. Can. J. Phys. 1980, 58, 1200-1211.
(25) Stephens, P. J.; Devlin, F. J.; Chabalowski, C. F.; Frisch, M. J. Ab-Initio Calculation of Vibrational Absorption and CircularDichroism Spectra Using Density-Functional Force-Fields. J. Phys. Chem. 1994, 98, 11623-11627.

(26) Frisch, M. J.; Schlegel, H. B.; Scuseria, G. E.; Robb, M. A.; Cheeseman, J. R.; Scalmani, G.; Barone, V.; Mennucci, B.; Petersson, G. A.; Nakatsuji, H.; Caricato, M.; Li, X.; Hratchian, H. P.; Izmaylov, A. F.; Bloino, J.; Zheng, G.; Sonnenberg, J. L.; Hada, M.; Ehara, M.; Toyota, K.; Fukuda, R.; Hasegawa, J.; Ishida, M.; Nakajima, T.; Honda, Y.; Kitao, O.; Nakai, H.; Vreven, T.; Montgomery, J. A., Jr.; Peralta, J. E.; Ogliaro, F.; Bearpark, M.; Heyd, J. J.; Brothers, E.; Kudin, K. N.; Staroverov, V. N.; Keith, T.; Kobayashi, R.; Normand, J.; Raghavachari, K.; Rendell, A.; Burant, J. C.; Iyengar, S. S.; Tomasi, J.; Cossi, M.; Rega, N.; Millam, J. M.; Klene, M.; Knox, J. E.; Cross, J. B.; Bakken, V.; Adamo, C.; Jaramillo, J.; Gomperts, R.; Stratmann, R. E.; Yazyev, O.; Austin, A. J.; Cammi, R.; Pomelli, C.; Ochterski, J. W.; Martin, R. L.; Morokuma, K.; Zakrzewski, V. G.; Voth, G. A.; Salvador, P.; Dannenberg, J. J.; Dapprich, S.; Daniels, A. D.; Farkas, O.; Foresman, J. B.; Ortiz, J. V.; Cioslowski, J.; Fox, D. J. Gaussian 09, Revision D.01; Gaussian, Inc.: Wallingford, CT, 2013.

(27) Frisch, M. J.; Schlegel, H. B.; Scuseria, G. E.; Robb, M. A.; Cheeseman, J. R.; Scalmani, G.; Barone, V.; Petersson, G. A.; Nakatsuji, H.; Li, X.; Caricato, M.; Marenich, A. V.; Bloino, J.; Janesko, B. G.; Gomperts, R.; Mennucci, B.; Hratchian, H. P.; Ortiz, J. V.; Izmaylov, A. F.; Sonnenberg, J. L.; Williams-Young, D.; Ding, F.; Lipparini, F.; Egidi, F.; Goings, J.; Peng, B.; Petrone, A.; Henderson, T.; Ranasinghe, D.; Zakrzewski, V. G.; Gao, J.; Rega, N.; Zheng, G.; Liang, W.; Hada, M.; Ehara, M.; Toyota, K.; Fukuda, R.; Hasegawa, J.; Ishida, M.; Nakajima, T.; Honda, Y.; Kitao, O., Nakai, H.; Vreven, T.; Montgomery, J. A., Jr.; Peralta, J. E.; Ogliaro, F.; Bearpark, M. J.; Heyd, J. J.; Brothers, E. N.; Kudin, K. N.; Staroverov, V. N.; Keith, T. A.; Kobayashi, R.; Normand, J.; Raghavachari, K.; Rendell, A. P.; Burant, J. C.; Iyengar, S. S.; Tomasi, J.; Cossi, M.; Millam, J. M.; Klene, M.; Adamo, C.; Cammi, R.; Ochterski, J. W.; Morokuma, K.; Farkas, O.; Foresman, J. B.; Fox, D. J. Gaussian 16, Revision A.03; Gaussian, Inc.: Wallingford CT, 2016.

(28) Lisgarten, J. N.; Potter, B. S.; Bantuzeko, C.; Palmer, R. A. Structure, absolute configuration, and conformation of the antimalarial compound, Artemisinin. J. Chem. Crystallogr. 1998, 28, 539543.

(29) Jasinski, J. P.; Butcher, R. J.; Narayana, B.; Swamy, M. T.; Yathirajan, H. S. A second polymorph of beta-arteether. Acta Crystallogr., Sect. E: Struct. Rep. Online 2008, 64, o187.

(30) Jasinski, J. P.; Butcher, R. J.; Narayana, B.; Swamy, M. T.; Yathirajan, H. S. Redetermination of dihydroartemisinin at 103 (2) K. Acta Crystallogr., Sect. E: Crystallogr. Commun. 2008, 64, o187.

(31) Sacchi, P.; Loconte, L.; Macetti, G.; Rizzato, S.; Lo Presti, L. Correlations of Crystal Structure and Solubility in Organic Salts: The Case of the Antiplasmodial Drug Piperaquine. Cryst. Growth Des. 2019, 19, 1399-1410.

(32) Kim, S.; Chen, J.; Cheng, T.; Gindulyte, A.; He, J.; He, S.; Li, Q.; Shoemaker, B. A.; Thiessen, P. A.; Yu, B.; Zaslavsky, L.; Zhang, J.; Bolton, E. E. PubChem 2019 update: improved access to chemical data. Nucleic Acids Res. 2019, 47, D1102-D1109.

(33) Zhang, J.; Zhang, H.; Wu, T.; Wang, Q.; van der Spoel, D. Comparison of Implicit and Explicit Solvent Models for the Calculation of Solvation Free Energy in Organic Solvents. J. Chem. Theory Comput. 2017, 13, 1034-1043.

(34) Sen, A.; Bouchet, A.; Lepère, V.; Le Barbu-Debus, K.; Scuderi, D.; Piuzzi, F.; Zehnacker-Rentien, A. Conformational Analysis of Quinine and Its Pseudo Enantiomer Quinidine: A Combined JetCooled Spectroscopy and Vibrational Circular Dichroism Study. J. Phys. Chem. A 2012, 116, 8334-8344.

(35) Marenich, A. V.; Cramer, C. J.; Truhlar, D. G. Universal Solvation Model Based on Solute Electron Density and on a Continuum Model of the Solvent Defined by the Bulk Dielectric Constant and Atomic Surface Tensions. J. Phys. Chem. B 2009, 113, $6378-6396$ 
(36) Chamberlin, A. C.; Levitt, D. G.; Cramer, C. J.; Truhlar, D. G. Modeling Free Energies of Solvation in Olive Oil. Mol. Pharm. 2008, 5, 1064-1079.

(37) Clemente, F. R. Personal Comunication Regarding Olive Oil Solvent Paramaters and the SMD Solvent Model; Gaussian Technical Support: Wallingford CT, 2014.

(38) Paul, W.; Giesen, D. J.; Cramer, C. J.; Truhlar, D. G. Minnesota Solvent Descriptor Database; Department of Chemistry and Supercomputer Institute, University of Minnesota: Minneapolis, MN 55455-0431, 1999.

(39) Sarver, J. G.; White, D.; Erhardt, P.; Bachmann, K. Estimating xenobiotic half-lives in humans from rat data: Influence of $\log \mathrm{P}$. Environ. Health Perspect. 1997, 105, 1204-1209.

(40) Toutain, P. L.; Bousquet-Melou, A. Plasma terminal half-life. J. Vet. Pharmacol. Therapeut. 2004, 27, 427-439.

(41) Broccatelli, F.; Aliagas, I.; Zheng, H. Why Decreasing Lipophilicity Alone Is Often Not a Reliable Strategy for Extending IV Half-life. ACS Med. Chem. Lett. 2018, 9, 522-527.

(42) Morrison, F. A. Obtaining Uncerttainty Measures on Slopes and Intercept of Least Squares Fit with excel's LINEST. 2014, h t t p s : / / pages.mtu.edu/ f morriso/ cm $3215 /$ UncertaintySlopeInterceptOfLeastSquaresFit.pdf (accessed on 28 October 2019).

(43) Avery, M. A.; Bonk, J. D.; Chong, W. K. M.; Mehrotra, S.; Miller, R.; Milhous, W.; Goins, D. K.; Venkatesan, S.; Wyandt, C.; Khan, I.; Avery, B. A. Structure-activity relationships of the antimalarial agent artemisinin .2. Effect of heteroatom substitution at O-11: Synthesis and bioassay of N-alkyl-11-aza-9-desmethylartemisinins. J. Med. Chem. 1995, 38, 5038-5044.

(44) Ramu, K.; Baker, J. K. Synthesis, Characterization, and Antimalarial Activity of the Glucuronides of the Hydroxylated Metabolites of Arteether. J. Med. Chem. 1995, 38, 1911-1921.

(45) Singh, C.; Chaudhary, S.; Puri, S. K. New orally active derivatives of artemisinin with high efficacy against multidrug-resistant malaria in mice. J. Med. Chem. 2006, 49, 7227-7233.

(46) Abraham, M. H.; William, E.; Acree, J. Descriptors for artemisinin and its derivatives: estimation of physicochemical and biochemical data. Eur. Chem. Bull. 2013, 2, 1027-1037.

(47) Warhurst, D. C.; Steele, J. C. P.; Adagu, I. S.; Craig, J. C.; Cullander, C. Hydroxychloroquine is much less active than chloroquine against chloroquine-resistant Plasmodium falciparum, in agreement with its physicochemical properties. J. Antimicrob. Chemother. 2003, 52, 188-193.

(48) CHMP. Assessment Report: Eurartesim, Dihydroartemisinin/ Piperqquine Phosphate, Procedure No.: EMEA/H/C/1199. Committee for Medicinal Products of Human Use 2011, section 2.3.5: Exotoxicity/environmental risk assessment, page 28.

(49) Strauch, S.; Jantratid, E.; Dressman, J. B.; Junginger, H. E.; Kopp, S.; Midha, K. K.; Shah, V. P.; Stavchansky, S.; Barends, D. M. Biowaiver Monographs for Immediate Release Solid Oral Dosage Forms: Mefloquine Hydrochloride. J. Pharm. Sci. 2011, 100, 11-21. (50) Wahajuddin; Raju, K. S. R.; Singh, S. P.; Taneja, I. Investigation of the Functional Role of P-Glycoprotein in Limiting the Oral Bioavailability of Lumefantrine. Antimicrob. Agents Chemother. 2014, 58, 489-494.

(51) Crowe, A.; Ilett, K. F.; Karunajeewa, H. A.; Batty, K. T.; Davis, T. M. E. Role of P glycoprotein in absorption of novel antimalarial drugs. Antimicrob. Agents Chemother. 2006, 50, 3504-3506.

(52) National Center for Biotechnology Information. PubChem Database. Artelinic acid, C., https://pubchem.ncbi.nlm.nih.gov/ compound/Artelinic-acid (accessed on Oct 13, 2019).

(53) Cheng, T.; Zhao, Y.; Li, X.; Lin, F.; Xu, Y.; Zhang, X.; Li, Y.; Wang, R.; Lai, L. Computation of octanol-water partition coefficients by guiding an additive model with knowledge. J. Chem. Inf. Model. 2007, 47, 2140-2148.

(54) Medhi, B.; Patyar, S.; Rao, R. S.; Byrav DS, P.; Prakash, A. Pharmacokinetic and Toxicological Profile of Artemisinin Compounds: An Update. Pharmacology 2009, 84, 323-332.
(55) Jittamala, P.; Pukrittayakamee, S.; Ashley, E. A.; Nosten, F.; Hanboonkunupakarn, B.; Lee, S. J.; Thana, P.; Chairat, K.; Blessborn, D.; Panapipat, S.; White, N. J.; Day, N. P. J.; Tarning, J. Pharmacokinetic Interactions between Primaquine and Pyronaridine-Artesunate in Healthy Adult Thai Subjects. Antimicrob. Agents Chemother. 2015, 59, 505-513.

(56) Bangchang, K. N.; Karbwang, J.; Thomas, C. G.; Thanavibul, A.; Sukontason, K.; Ward, S. A.; Edwards, G. Pharmacokinetics of Artemether after Oral-Administration to Healthy Thai Males and Patients with Acute, Uncomplicated Falciparum-Malaria. Br. J. Clin. Pharmacol. 1994, 37, 249-253.

(57) Sabarinath, S. N.; Asthana, O. P.; Puri, S. K.; Srivastava, K.; Madhusudanan, K. P.; Gupta, R. C. Clinical pharmacokinetics of the diastereomers of arteether in healthy volunteers. Clin. Pharmacokinet. 2005, 44, 1191-1203.

(58) Si, Y.; Li, Q.; Xie, L.; Bennett, K.; Weina, P. J.; Mog, S.; Johnson, T. O. Neurotoxicity and toxicokinetics of artelinic acid following repeated oral administration in rats. Int. J. Toxicol. 2007, 26, 401-410.

(59) Orrell, C.; Little, F.; Smith, P.; Folb, P.; Taylor, W.; Olliaro, P.; Barnes, K. I. Pharmacokinetics and tolerability of artesunate and amodiaquine alone and in combination in healthy volunteers. Eur. J. Clin. Pharmacol. 2008, 64, 683-690.

(60) Tarning, J.; Lindegardh, N.; Annerberg, A.; Singtoroj, T.; Day, N. P. J.; Ashton, M.; White, N. J. Pitfalls in estimating piperaquine elimination. Antimicrob. Agents Chemother. 2005, 49, 5127-5128.

(61) Moore, B. R.; Page-Sharp, M.; Stoney, J. R.; Ilett, K. F.; Jago, J. D.; Batty, K. T. Pharmacokinetics, Pharmacodynamics, and Allometric Scaling of Chloroquine in a Murine Malaria Model. Antimicrob. Agents Chemother. 2011, 55, 3899-3907.

(62) Babalola, C. P.; Bolaji, O. O.; Ogunbona, F. A.; Sowunmi, A.; Walker, O. Dose linearity of quinine in healthy human subjects. Eur. J. Pharm. Biopharm. 1997, 44, 143-147.

(63) Nosten, F.; White, N. J. Artemisinin-based combination treatment of falciparum malaria. Am. J. Trop. Med. Hyg. 2007, 77, 181-192.

(64) Lefêvre, G.; Thomsen, M. S. Clinical pharmacokinetics of artemether and lumefantrine (Riamet (R)). Clin. Drug Invest. 1999, $18,467-480$.

(65) Ochs, H. R.; Greenblatt, D. J.; Woo, E.; Franke, K.; Pfeifer, H. J.; Smith, T. W. Single and Multiple Dose Pharmacokinetics of Oral Quinidine Sulfate and Gluconate. Am. J. Cardiol. 1978, 41, 770-777.

(66) Sabarinath, S.; Madhusudanan, K. P.; Gupta, R. C. Pharmacokinetics of the diastereomers of arteether, a potent antimalarial drug, in rats. Biopharm. Drug Dispos. 2005, 26, 211-223.

(67) Niklaus, M. C. Online SMILES Translator and Structure File Generator; NIH National Cancer Institure/CADD Group, Update: Oct 10, 2017, https://cactus.nci.nih.gov/translate/2017.

(68) Aziz, M. H. Piperaquine and Metabolites Bioanalysis and Pharmacokinetics; Department of Pharmacology, Institute of Neuroscience and Physiology at Salgrenska Academy, University of Gothenburg: Gottenburg, Sweden, ISBN 978-629-02520-0, 2017.

(69) Colussi, D.; Parisot, C.; Legay, F.; Lefevre, G. Binding of artemether and lumefantrine to plasma proteins and erythrocytes. Eur. J. Pharm. Sci. 1999, 9, 9-16.

(70) Zsila, F.; Visy, J.; Mády, G.; Fitos, I. Selective plasma protein binding of antimalarial drugs to alpha(1)-acid glycoprotein. Bioorg. Med. Chem. 2008, 16, 3759-3772.

(71) Ofori-Adjei, D.; Ericsson, Ö.; Lindström, B.; Hermansson, J.; Adjepon-Yamoah, K.; Sjöqvist, F. Enantioselective Analysis of Chloroquine and Desethylchloroquine after Oral-Administration of Racemic Chloroquine. Ther. Drug Monit. 1986, 8, 457-461.

(72) Krishna, S.; White, N. J. Pharmacokinetics of quinine, chloroquine and amodiaquine - Clinical implications. Clin. Pharmacokinet. 1996, 30, 263-299.

(73) Silamut, K.; Molunto, P.; Ho, M.; Davis, T.; White, N. Alpha-1Acid Glycoprotein (Orosomucoid) and Plasma-Protein Binding of Quinine in Falciparum-Malaria. Br. J. Clin. Pharmacol. 1991, 32, 311315 . 
(74) Purser, S.; Moore, P. R.; Swallow, S.; Gouverneur, V. Fluorine in medicinal chemistry. Chem. Soc. Rev. 2008, 37, 320-330.

(75) Urien, S.; Giroud, Y.; Tsai, R. S.; Carrupt, P. A.; Brée, F.; Testa, B.; Tillement, J. P. Mechanism of Ligand-Binding to Alpha(1)-Acid Glycoprotein (Orosomucoid) - Correlated Thermodynamic Factors and Molecular-Parameters of Polarity. Biochem. J. 1995, 306, 545549.

(76) Batty, K. T.; Ilett, K. F.; Davis, T. M. E. Protein binding and alpha :beta anomer ratio of dihydroartemisinin in vivo. Br. J. Clin. Pharmacol. 2004, 57, 529-533.

(77) White, N. J.; van Vugt, M.; Ezzet, F. Clinical pharmacokinetics and pharmacodynamics of artemether-lumefantrine. Clin. Pharmacokinet. 1999, 37, 105-125.

(78) Li, Q.; Weina, P.; Zhang, J.; Haeberle, A.; Xie, L. H. The evaluation of radiolabeled artesunate on tissue distribution in rats and protein binding in humans. Am. J. Trop. Med. Hyg. 2006, 75, 817826.

(79) Wanwimolruk, S.; Edwards, G.; Ward, S. A.; Breckenridge, A. M. The Binding of the Antimalarial Arteether to Human PlasmaProteins Invitro. J. Pharm. Pharmacol. 1992, 44, 940-942.

(80) Jafery, N.; Najmi, M. H. Pharmacokinetics of lumefantrine in healthy Pakistani volunteers. Pakistan Armed Forces Med. J. 2011, (), 61 .

(81) Annerberg, A.; Lwin, K. M.; Lindegardh, N.; Khrutsawadchai, S.; Ashley, E.; Day, N. P. J.; Singhasivanon, P.; Tarning, J.; White, N. J.; Nosten, F. A Small Amount of Fat Does Not Affect Piperaquine Exposure in Patients with Malaria. Antimicrob. Agents Chemother. 2011, 55, 3971-3976.

(82) Bhattacharjee, A. K.; Karle, J. M. Stereoelectronic properties of antimalarial artemisinin analogues in relation to neurotoxicity. Chem. Res. Toxicol. 1999, 12, 422-428.

(83) Brossi, A.; Venugopalan, B.; Dominguez Gerpe, L.; Yeh, H. J. C.; Flippen-Anderson, J. L.; Buchs, P.; Luo, X. D.; Milhous, W.; Peters, W. Arteether, a New Antimalarial Drug - Synthesis and Antimalarial Properties. J. Med. Chem. 1988, 31, 645-650.

(84) Pareek, A.; Mathur, P. C.; Patel, K. H.; Mishra, S. K.; Kochar, D.; Nandy, A. Efficacy and safety of beta-arteether and alpha/betaarteether for treatment of acute Plasmodium falciparum malaria. Am. J. Trop. Med. Hyg. 2006, 75, 139-142.

(85) D’Acquarica, I.; Gasparrini, F.; Kotoni, D.; Pierini, M.; Villani, C.; Cabri, W.; Mattia, M. D.; Giorgi, F. Stereodynamic Investigation of Labile Stereogenic Centres in Dihydroartemisinin. Molecules 2010, $15,1309-1323$. 